\title{
Neurophilic Descending Migration of Dorsal Midbrain Neurons Into the Hindbrain
}

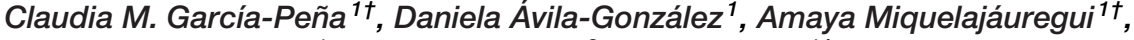 \\ Carlos Lozano-Flores ${ }^{1}$, Grant S. Mastick ${ }^{2}$, Elisa Tamariz ${ }^{1 \dagger}$ and Alfredo Varela-Echavarría ${ }^{1 *}$ \\ ${ }^{1}$ Department of Developmental Neurobiology and Neurophysiology, Instituto de Neurobiología, Universidad Nacional \\ Autónoma de México (UNAM), Querétaro, Mexico, ${ }^{2}$ Department of Biology, University of Nevada, Reno, Reno, NV, \\ United States
}

\section{OPEN ACCESS}

Edited by:

Luis Puelles,

Universidad de Murcia, Spain

Reviewed by: Antón Barreiro-Iglesias, Universidade de Santiago de Compostela, Spain

Fernando de Castro, Instituto Cajal (IC), Spain

*Correspondence: Alfredo Varela-Echavarría avarela@unam.mx

${ }^{\dagger}$ Present address: Claudia M. García-Peña, Department of Biology, University of Nevada, Reno, Reno, NV, United States

Amaya Miquelajáuregui, Institute of Neurobiology, University of

Puerto Rico-Medical Sciences Campus, San Juan, Puerto Rico Elisa Tamariz, Departamento de Biomedicina, Instituto de Ciencias de la Salud Universidad Veracruzana, Xalapa,

Mexico

Received: 07 June 2018 Accepted: 22 October 2018 Published: 13 November 2018

Citation: García-Peña CM, Ávila-González D, Miquelajáuregui A, Lozano-Flores $C$, Mastick GS, Tamariz E and Varela-Echavarría A (2018) Neurophilic Descending Migration of Dorsal Midbrain Neurons Into the Hindbrain.

Front. Neuroanat. 12:96. doi: 10.3389/fnana.2018.00096
Stereotypic cell migrations in the developing brain are fundamental for the proper patterning of brain regions and formation of neural networks. In this work, we uncovered in the developing rat, a population of neurons expressing tyrosine hydroxylase (TH) that migrates posteriorly from the alar plate of the midbrain, in neurophilic interaction with axons of the mesencephalic nucleus of the trigeminal nerve. A fraction of this population was also shown to traverse the mid-hindbrain boundary, reaching the vicinity of the locus coeruleus (LC) in rhombomere 1 ( $r$ 1). This migratory population, however, does not have a noradrenergic (NA) phenotype and, in keeping with its midbrain origin, expresses Otx2 which is down regulated upon migration into the hindbrain. The interaction with the trigeminal mesencephalic axons is necessary for the arrangement and distribution of migratory cells as these aspects are dramatically altered in whole embryo cultures upon disruption of trigeminal axon projection by interfering with DCC function. Moreover, in mouse embryos in an equivalent developmental stage, we detected a cell population that also migrates caudally within the midbrain apposed to mesencephalic trigeminal axons but that does not express TH; a fraction of this population expresses calbindin instead. Overall, our work identified $\mathrm{TH}$-expressing neurons from the rat midbrain alar plate that migrate tangentially over long distances within the midbrain and into the hindbrain by means of a close interaction with trigeminal mesencephalic axons. A different migratory population in this region and also in mouse embryos revealed diversity among the cells that follow this descending migratory pathway.

Keywords: embryo, migration, tyrosine hydroxylase, calbindin, neurophilic, midbrain, rat, mouse

\section{INTRODUCTION}

Early brain development is characterized by extensive neuronal migration, sometimes over long distances, following stereotypic routes and during precise time-windows. These migrations are crucial for the proper patterning of neural networks and their disruption has been implicated in numerous neuro-developmental disorders, such as schizophrenia (Lencz et al., 2013; Rakić et al., 2015), autism (Chuang et al., 2015), bipolar and depressive disorder (Goossens et al., 2003; Bertram et al., 2007; Li et al., 2011), mental disability and epilepsy (Reuter et al., 2014).

Based on the direction of displacement, neuronal migration has been defined as radial or tangential (Rakic, 1990; Marín and Rubenstein, 2003). Radial displacement occurs when cells from the ventricular germinal zone slide along the fibers of radial glia to reach the marginal zone 
and pial surface. This is also known as gliophilic migration and is important for the formation of layers in the developing cortex, hippocampus, cerebellum, diencephalon, brainstem and spinal cord (Rakic, 1971, 1990; de Carlos et al., 1996). Tangential migration is observed as neuroblasts move over the developing brain in routes parallel to the pial surface, as was demonstrated for cortical GABAergic interneurons and locus coeruleus (LC) noradrenergic (NA) neurons (Tanaka et al., 2006; Shi et al., 2008). Tangential migration can also occur along axons ("neurophilic" migration; Rakic, 1990; Nadarajah and Parnavelas, 2002; Ghashghaei et al., 2007) or move in chains following different substrates or signals from the brain microenvironment (Marín and Rubenstein, 2003). Tangential migration can take place over long distances and across regional borders in the brain, as has been shown for neurons moving from the diencephalon to the telencephalon, from the ganglionic eminences to the cortex, from the diencephalic-telencephalic boundary rostrally into the telencephalon, and from the hindbrain to the pontine tegmentum (Letinic and Rakic, 2001; Aroca et al., 2006; Shi et al., 2008; Miquelajáuregui et al., 2010).

In the anterior region of the brainstem, a diversity of neuronal types has been described that includes dopaminergic (DA; Simon et al., 2001; Chinta and Andersen, 2005; Prakash and Wurst, 2006), GABAergic, glutamatergic (Lahti et al., 2013), and NA neurons (Aroca et al., 2006). The phenotype decision of the neuroepithelial progenitors leading to each neuronal group depends upon the positional information in each of the morphogenetic territories and the concentration of signals that generate gradients in the anterior/posterior and in the dorsal/ventral axes. In the anterior brainstem, ventral expression of Shh and dorsal expression of Wnt1 intersect the region where Otx2 expression in the midbrain abuts Gbx2 expression in the rhombomere $1(\mathrm{r} 1)$ of the hindbrain ( $\mathrm{Li}$ and Joyner, 2001; Inoue et al., 2012). At this juncture, the isthmic organizer, or mid-hindbrain boundary region (MHB) is established, thus influencing the region's morphogenesis via secretion of Wnt1, predominantly from the posterior boundary of the midbrain and FGF8 from the anterior edge of the hindbrain (Joyner et al., 2000). These signals are part of complex pathways such as those that lead to the differentiation of catecholaminergic neuron types; DA neurons in the midbrain and NA neurons in $\mathrm{r}$, both of which can be identified by expression of tyrosine hydroxylase (TH), a common enzyme in the biosynthetic routes of catecholamines (Prakash et al., 2006).

Migration of these neuronal types has been observed in the developing brainstem. Progenitors of some DA neurons migrate first radially and then tangentially (subpially) from the floor plate ventricular zone to the basal plate marginal zone forming the substantia nigra pars compacta, while some of these floor plate cells populate the ventral tegmental area (VTA) after a short radial migration (Yang et al., 2013; Bodea et al., 2014). These processes of DA precursor cell migration have been linked to the function of the netrin receptor DCC (Xu et al., 2010). At a later stage, GABAergic neurons populate the VTA using DA axons to reach their final location (Vasudevan et al., 2012). Other studies showed as well that NA neurons migrate ventrally from the ventral alar plate of $\mathrm{r} 1$ to their final location in the LC involving Netrin/DCC signaling (Shi et al., 2008).

In this work, we uncovered a population of neurons expressing $\mathrm{TH}$ that originates in the alar plate of the midbrain and migrates posteriorly along a longitudinal route in close apposition to axons of the trigeminal mesencephalic nucleus $(\mathrm{TmesV})$ thus constituting a neurophilic migration. Some neurons from this population reach the anterior $\mathrm{rl}$ region adjacent to the prospective LC in the hindbrain. In mouse embryos, similarly neurophilic migrating populations were detected that lack TH and one of them instead expresses calbindin, revealing heterogeneity among the descending migratory cells in this region.

\section{MATERIALS AND METHODS}

\section{Animals}

Wistar rats were housed and used at Universidad Nacional Autónoma de México (UNAM) according to regulations of the Mexican government regarding the use of laboratory animals for research purposes (NOM-062-ZOO-1999). This protocol was approved by the Institute's Research Ethics Commitee (Comité de Ética en la Investigación, INB-UNAM) with register \#001. Animals were killed with $\mathrm{CO}_{2}$ and by cervical dislocation by trained personnel at various gestational days, using the morning of the day of detection of the vaginal plug as embryonic day (E) 0.5. For every experiment, 5-10 embryos for each condition were analyzed.

DCC mutant mice maintained at University of Nevada, Reno were a kind gift of Frederic Charron (ICMR, Montreal, CA, Canada). The mice were euthanized following NIH guidelines according to protocol \#2015-00435. DCC genotyping was performed as previously described (Fazeli et al., 1997).

\section{Immunofluorescence}

For whole brain immunostaining, embryos were fixed for $4 \mathrm{~h}$ in $3.5 \%$ paraformaldehyde (PFA) in phosphate buffer saline (PBS; 70011-044, Gibco, Life Technologies, Grand Island, NY, USA). Embryos were then washed 10 times per $10 \mathrm{~min}$ each in PBS and the brains were extracted. Brains were treated with $0.3 \%$ Triton X-100 in PBS for $30 \mathrm{~min}$ and then incubated for $30 \mathrm{~min}$ in $10 \%$ goat serum (16210072, Gibco) or horse serum (26050070, Gibco) in PBS. After five washes of $10 \mathrm{~min}$ each in $\mathrm{PBS}$, brains were incubated at $4^{\circ} \mathrm{C}$ for $16 \mathrm{~h}$ with primary antibodies diluted in $1 \%$ Triton X-100 in PBS for membrane proteins or 3\% Triton X-100 in PBS for transcription factors, both containing 5\% horse or goat serum. Brains were then washed 10 times for $10 \mathrm{~min}$ each followed by an incubation with horse or goat serum in PBS as described above. Incubation for $1 \mathrm{~h}$ with secondary antibodies $(1: 1,000)$ diluted in PBS was followed by 10 washes for $10 \mathrm{~min}$ each in PBS. Brains were then hemisected by cutting along dorsal and ventral midlines and mounted flat in coverslips in $0.4 \mathrm{mg} / \mathrm{ml}$ DABCO $33 \mathrm{LV}$ (290734, Sigma-Aldrich, St. Louis, MO, USA) in 10\% glycerol (g9012, Sigma-Aldrich) in PBS with the pial side up. Boundaries between the different brain regions 
were defined based on the morphology of the flat-mounted specimens.

For immunostaining on brain sections, embryos were fixed in 3.5\% PFA in PBS, washed as mentioned above, cryoprotected in 30\% sucrose in PBS, and frozen in Tissue-Tek (Sakura Finetek, Torrance, CA, USA). Cryostat sections $(20 \mu \mathrm{m})$ were then obtained and collected in Fisherbrand Superfrost Plus Microscope Slides (Fisher Scientific International, Pittsburgh, $\mathrm{PE}, \mathrm{USA}$ ). The sections were dried up for $4 \mathrm{~h}$ at room temperature and stored at $-20^{\circ} \mathrm{C}$ until use. For immunostaining, sections were washed several times in PBS, incubated for $30 \mathrm{~min}$ in 5\% goat or horse serum in PBS, and then washed three times for 5 min each with PBS. Incubation of primary antibodies was performed for $16 \mathrm{~h}$ in $1 \%$ Triton X-100 in PBS containing 5\% horse or goat serum at $4^{\circ} \mathrm{C}$. The sections were then washed with PBS three times for $5 \mathrm{~min}$ each. The sections were then incubated with secondary antibodies at room temperature for $1 \mathrm{~h}$ in PBS containing 5\% horse or goat serum. After incubation, sections were washed with PBS five times for 5 min each and mounted with coverslips with $\mathrm{DABCO} /$ glycerol as described above.

The primary antibodies and registry IDs ${ }^{1}$ for the following protein targets and dilutions were: TH made in rabbit (1:1,000, AB_2617184, Pel-Freez, Rogers, AR, USA); TH made in sheep (1:150, AB_461070, Pel-Freez); calbindin D28K (1:500, AB_2068336, Millipore, Billerica, MA, USA); DBH made in mouse (1:500, AB_2245740, Millipore); Otx2 made in rabbit (1:500, AB_776930, Abcam, Cambridge, MA, USA); Phox2a made in mouse (1:400, AB_944807, Abcam); Phox2b made in rabbit (1:400, AB_10675986, Abcam); and $\beta$-III-Tubulin made in mouse (1:2,000, AB_2313773, Covance, Princeton, NJ, USA).

The secondary antibodies used were: Alexa-Fluor 488 goat anti-mouse (1:1,000, AB_138404, Invitrogen, Eugene, OR, USA), Alexa-Fluor 488 goat anti-rabbit (AB_2576217, Invitrogen), Alexa-Fluor 488 donkey anti-sheep (AB_141362, Invitrogen), Cy3 goat anti-mouse (AB_2340817, Jakson ImmunoResearch, West Grove, PA, USA) and Cy3 goat anti-rabbit (AB_955021, Abcam). For chromogenic immunostaining, peroxidase anti-rabbit (AB_90264, Millipore) secondary antibodies were used and revealed with diaminobencidine (DAB; D8001, SigmaAldrich) and hydrogen peroxide (216763, Sigma-Aldrich).

\section{Image Acquisition}

Three different confocal microscopes were used: Nikon Eclipse E600 PCM 2000 (Figures 1A-C, 2, 6), Zeiss LSM510 META (Figures 1E,F, Figures 3-6, 7A,B,D,E, 8A,C,D,F-I). Figures 7F,G were taken with the Leica TCS confocal microscope. Unless otherwise indicated, for each image Z-stacks of pictures $1.5 \mu \mathrm{m}$ apart were taken with a total of 20-30 pictures per sample; some stacks were then projected to a single image to show the entire signal present in the tissue. For orthogonal pictures, Z-stacks were digitally rotated $90^{\circ} \mathrm{C}$ and cut digitally in different areas of the sample to show co-localization of fluorescent labels in a single frame. Volume reconstruction

${ }^{1}$ http://antibodyregistry.org
(3D) of confocal Z-series was performed with Image ${ }^{2}$ followed by Amira 6.4.0 (Thermo Fisher Scientific) using its isosurface function.

\section{Cell Lineage Labeling and Quantitation}

To trace the migration of cells from their place of origin, we injected in whole embryos the lipophilic dye carboxyl-fluorescein di-acetate (CFDA, SE, 557 M.W., V12883, Invitrogen; $10 \mathrm{mM}$ diluted in DMSO 472301, Sigma-Aldrich) which only fluoresces upon cell entry (García-Moreno et al., 2010). Injections were made in rat embryos at E11.5 and in mouse embryos at 9.5 in different areas of the ventricular surface of the diencephalon or midbrain, followed by incubation for $24 \mathrm{~h}$ in blood serum obtained from Wistar rats with a constant flow of a gas mix of $95 \% \mathrm{O}_{2}$ and $5 \% \mathrm{CO}_{2}$. After incubation, embryos were fixed with 3.5\% PFA in PBS for $4 \mathrm{~h}$ and immunostaining was performed as described above.

To quantitate the migratory cells from various regions of the midbrain, ventricular injections were applied at the locations indicated in Figure $2 \mathrm{~K}$ followed by TH immunostaining and flatmounting. For each injection, Z-stacks of confocal images were obtained from regions containing all CFDA labeled cells that migrated away from the labeling point among which $\mathrm{TH}^{+}$and $\mathrm{TH}^{-}$cells were counted. Results were analyzed with the program JASP 0.8.6.0 and JASB 0.9.0.1 applying an ANOVA with post hoc Tukey test. The number of injections analyzed for each region indicated in Figure 2 were: DI, 2; 1, 3; 2, 4; 3, 3; 4, 3; and 5, 3.

\section{Retrograde Labeling With a Fluorescent Dye}

For the retrograde labeling we employed a variant of a method described previously (Auclair et al., 1999). Rat embryos were extracted from the pregnant rat female and placed in ice-cold DMEM/F12 (51445C, SIGMA). Embryos were immobilized with minutien pins on a $60 \mathrm{~mm}$ petri dish with a bed of silicon gel submerged in the same medium with one of their sides facing up. The ectoderm and mesenchyme were removed to expose the trigeminal ganglion which was then severed with the tip of a minutien pin laden with Dextran Alexa Fluor 488, 10,000 MW (D-22910; Molecular Probes, Invitrogen). After $3 \mathrm{~min}$, the petri dish was immersed in $250 \mathrm{ml}$ of medium at $25^{\circ} \mathrm{C}$, bubbled with a gas mixture of $95 \% \mathrm{O}_{2}$ and $5 \% \mathrm{CO}_{2}$ for $3 \mathrm{~h}$, and fixed with 3.5\% PFA and immunostained as described above.

\section{Blocking DCC-Mediated Signaling in Cultured Embryos}

To block the function of DCC in cultured embryos, we added the DCC-Fc chimeric protein $(20 \mathrm{ng} / \mathrm{ml}, 844-\mathrm{DC}-050$, R\&D Systems, Minneapolis, MN, USA) to the incubation medium of whole embryos in culture as described elsewhere (García-Peña et al., 2014). After incubation for $24 \mathrm{~h}$, embryos were fixed, whole brains were immunostained, and hemibrains mounted flat as described above. For control experiments, Recombinant Human IgG1 Fc (110-Hg-1-100, R\&D Systems) was used at $20 \mathrm{ng} / \mathrm{ml}$

${ }^{2}$ https://imagej.nih.gov 

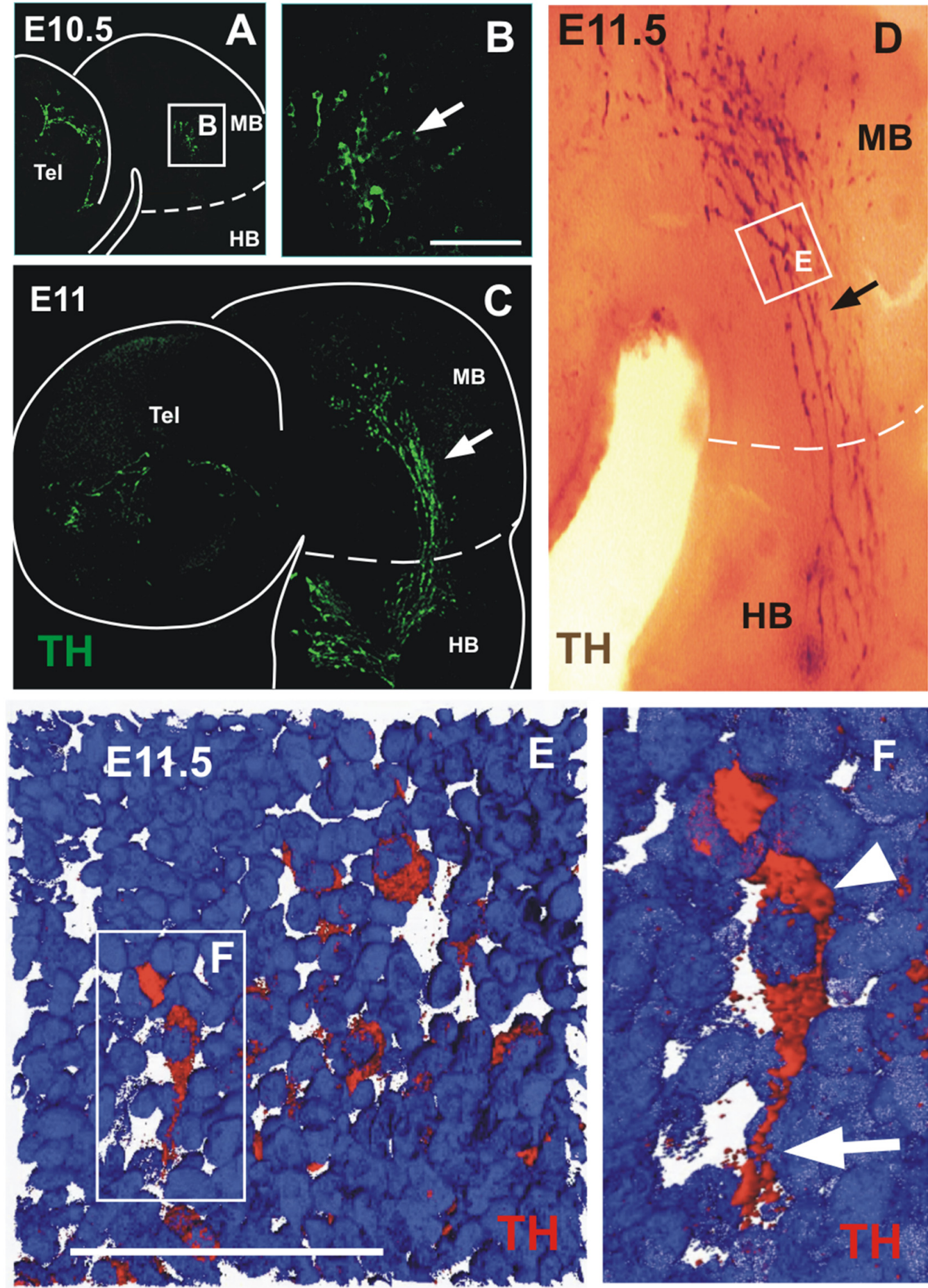

FIGURE 1 | A novel population of tyrosine hydroxylase (TH)-expressing cells in the midbrain alar plate. Immunofluorescent staining for TH in flat-mounted E10.5-11.5 hemi-brains is shown in (A-F). In all panels, rostral is to the left and dashed lines indicate the approximate location of the mid-hindbrain boundary region (MHB). Arrows in (A,C,D) indicate the location of the TH-expressing cell population that is present in the hindbrain from E10.5 to E11.5. (B,E,F) Magnified views of the areas indicated by frames in (A,D,F), respectively. (D) TH chromogenic immunostaining (not flat-mounted) revealing the location of the midbrain $\mathrm{TH}^{+}$cell population that is continuous into the hindbrain. (E) Volume reconstruction (3D) of a $\mathrm{Z}$ confocal series of a magnified region of the $\mathrm{TH}^{+}$cell cluster showing a few stained cells (red) and cell nuclei stained with DAPI in blue. This image was obtained from a parasaggittal cryosection of approximate location as indicated in (E,F). Single $\mathrm{TH}^{+}$cell showing its leading process (arrow) toward the hindbrain as observed in most individually identified neurons revealing a precise pattern in this cell group; its cell body containing the nucleus is indicated by the arrowhead. MB, midbrain; HB, hindbrain; Tel, telencephalic vesicle. Scale bars: $100 \mu \mathrm{m}$. 


\section{TH / CFDA $\quad$ E11 + 24 hours in culture}
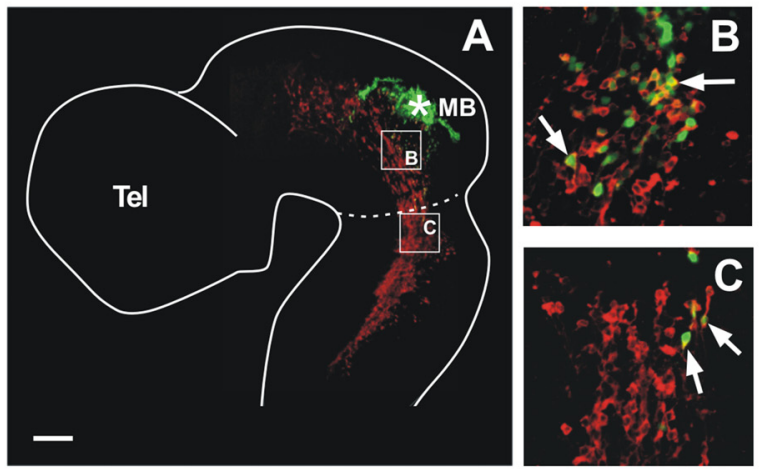
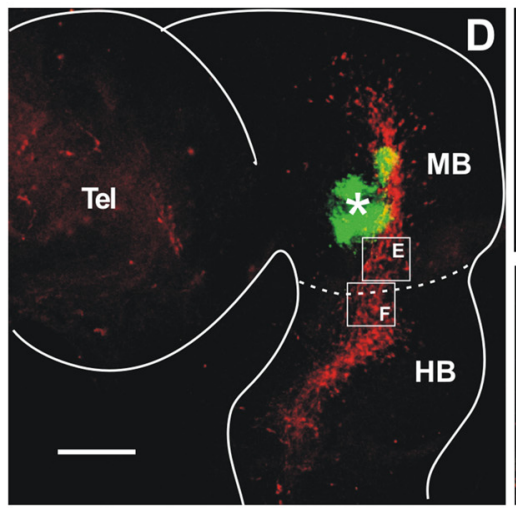

L
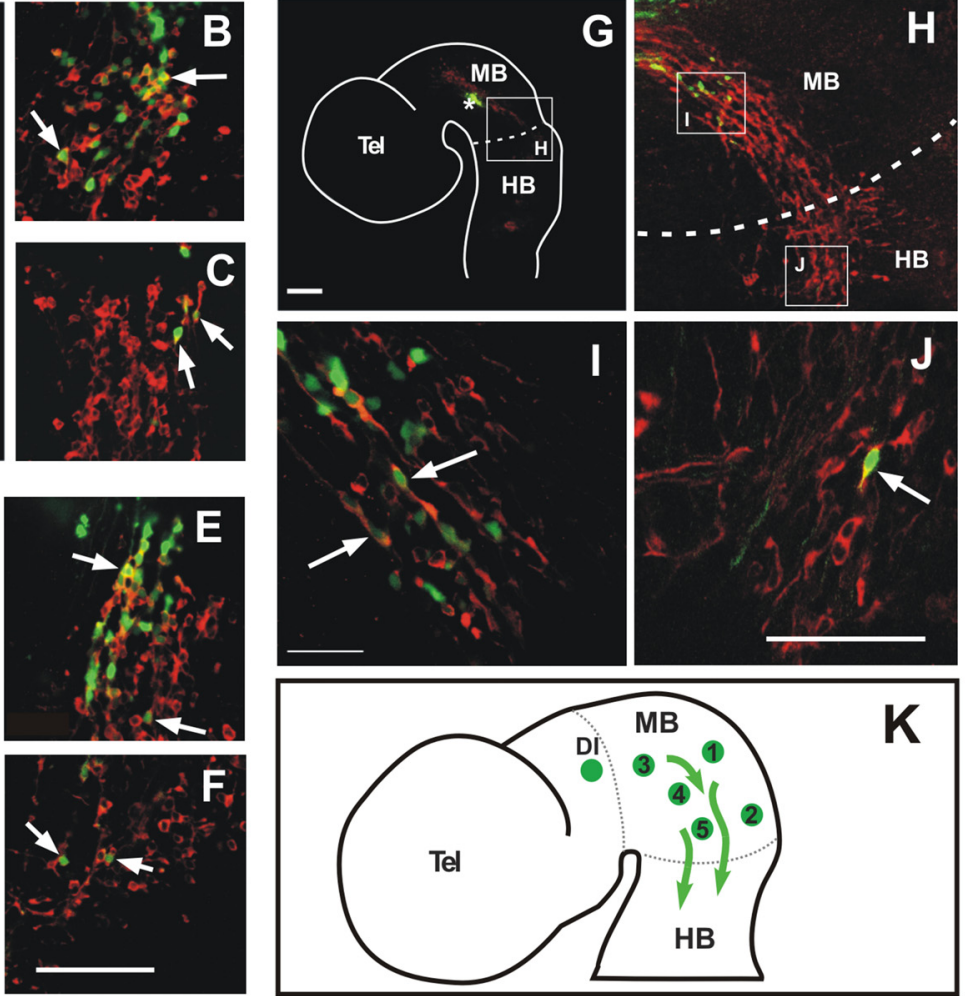

$$
\text { 旁。 }
$$

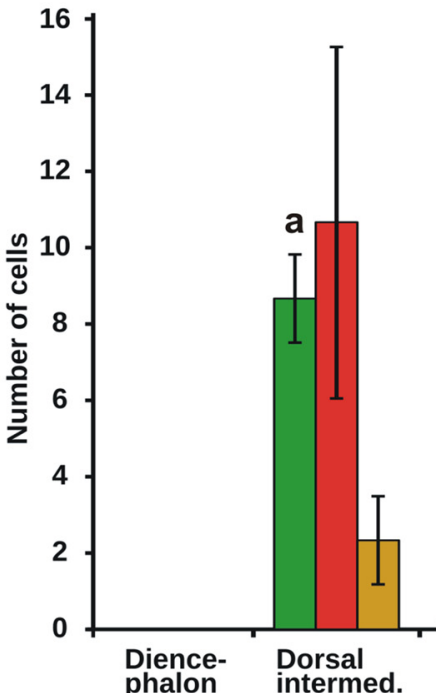

phalon

inter 1

1

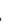

\section{Midbrain alar plate}

FIGURE 2 | TH cells from the alar plate of the midbrain migrate descendingly and some reach the anterior end of the hindbrain. Flat-mounted hemibrains of embryos injected with carboxyl-fluorescein di-acetate (CFDA, green) at various positions of the midbrain (indicated with asterisks) and cultured for $24 \mathrm{~h}$, followed by TH immunostaining (red). In all panels, rostral is to the left and dashed lines indicate the approximate location of the MHB. (A-C) Labeling from the dorsal aspect of the midbrain reveals CFDA $/ / \mathrm{TH}^{+}$cells that migrate ventrally into the $\mathrm{TH}^{+}$cell cluster and in a posterior direction along the cluster. Labeling from the posterior end of the midbrain (D,E) and from an intermediate position along its antero-posterior extent (G-J), reveal CFDA ${ }^{+} / \mathrm{TH}^{+}$cells that migrate in a posterior direction along the ventral region of the alar plate. From all labeled positions shown, cells were observed to reach the anterior region of the hindbrain (arrows in $\mathbf{C , F , J ) . ~ ( B , C , E , F , I , J ) ~}$

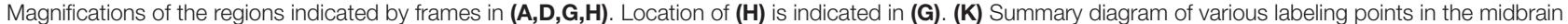
(green circles) and the direction of migration (arrows). Numbers in the diagram correspond to labeling regions in the midbrain alar plate indicated in (L). The green 


\section{FIGURE 2 | Continued}

circle in the diencephalon in $\mathbf{( K )}$ indicates labeling at the pretectum from which no migratory cells were observed (not shown). Panel (L) shows the quantitation of CFDA-labeled cells from various regions in the midbrain alar plate. Total migratory cells include all labeled cells that could be identified away from the labeling points; these include cells that were observed in the midbrain that do not express $\mathrm{TH}\left(\mathrm{TH}^{-}\right.$in $\left.\mathrm{MB}\right)$, cells in the midbrain that express $\mathrm{TH}\left(\mathrm{TH}^{+}\right.$in $\left.\mathrm{MB}\right)$, and cells that express $\mathrm{TH}$ that reached the anterior region of $r 1$ in the hindbrain $\left(\mathrm{TH}^{-}\right.$in $\left.\mathrm{HB}\right)$. Standard deviation is indicated in each of the bars. Value (a) indicates significant difference $(p<0.01)$ from 2,4 and 5; (b) difference from 2 and 4 and (c) difference from 1, 2 and 4. Number of injections indicated in "Materials and Methods" section. Scale bars: $100 \mu \mathrm{m}$. Bar in (F) also applies to (B,C,E); bar in $(\mathbf{J})$ also applies to (I).

as in previous studies (Liu et al., 2011; Czajkowsky et al., 2012; García-Peña et al., 2014). To quantitate the effect of DCC-Fc on the TmesV axon bundles, four Z-stacks per experimental condition (36 confocal planes, $0.7 \mu \mathrm{m}$ apart) were obtained of a microscope field of $225 \times 225 \mu \mathrm{m}$ (4.551 pixels/ $\mu \mathrm{m})$ of the intermediate ventral region on the midbrain alar plate, images were projected onto a single plane, the automatic Yen threshold method of Image $)^{3}$ was used to convert all images from grayscale to black and white and the total area occupied by the axon bundles was measured for each image. The WilcoxonMann-Whitney test calculator (Marx et al., 2016) was employed to assess statistical differences between controls and Fc-DCC treated cultures.

\section{Analysis of DCC Mutant Embryos}

For the analysis of Tmes $\mathrm{V}$ axon distribution in control and DCC mutant embryos, brains were extracted, immunostained for $\beta$-III-Tubulin (1:2,000, AB_2313773, Covance), and hemibrains were mounted flat. The distance from the center of the TmesV axon bundle to the dorsal edge of the brain was measured at the isthmic region for five wild-type and five mutant embryos. The Wilcoxon-Mann-Whitney test calculator (Marx et al., 2016) was employed to assess statistical differences between controls and mutant embryos.

\section{RESULTS}

\section{TH-Expressing Cells Migrate From the Midbrain to the Hindbrain in Rat Embryos}

Analyzing cells expressing $\mathrm{TH}$ in the developing rat midbrain, we detected a population that precedes the appearance of the widely studied ventral DA neurons of the substantia nigra and VTA. At E10.5, a few scattered $\mathrm{TH}^{+}$cells appear in the alar plate of the midbrain and in the telencephalon (Figures 1A,B). After $12 \mathrm{~h}$, and remaining up to E11.5, cells in the midbrain increase in number and display a distinctive elongated morphology and a clustered cell arrangement stretching from the anterior end of the midbrain to the anterior end of the hindbrain (Figures 1C,D). This cell distribution and the caudal orientation of their elongated cell processes (Figures 1E,F), suggested a migratory stream along the ventral border of the

\footnotetext{
${ }^{3}$ https://imagej.nih.gov
}

alar region that extended to the hindbrain region containing the prospective LC (Shi et al., 2008). Half a day later, at E12, the $\mathrm{TH}^{+}$cells were no longer detected in the alar plate of the midbrain but a distinct cluster remains in the alar plate of $\mathrm{rl}$ (not shown). Hence, these $\mathrm{TH}$ cells are an early-born population emanating from the alar aspect of the rat midbrain that seems to migrate to the hindbrain by E11.5.

To test directly the idea that this midbrain $\mathrm{TH}^{+}$lineage is indeed migratory, and to characterize its possible displacement pathway, we performed labeling in several regions of the ventricular germinal zone of E11 embryos using the fluorescent cell tracer CFDA. After $24 \mathrm{~h}$ in culture, we found that the labeled midbrain progenitors gave rise to $\mathrm{TH}$-expressing cells that migrated tangentially in a posterior direction from the injection sites (Figure 2). Labeling along the longitudinal extent of the $\mathrm{TH}^{+}$domain revealed the caudal migration (Figures 2D-J) and even the dorsal-most midbrain region showed a contribution to this migratory population (Figures 2A-C). Strikingly, from most labeling points cells were observed to descend hundreds of micrometers into the anterior region of $\mathrm{r} 1$ adjacent to the prospective LC (Figures 2C,F,J).

Quantitation of the CFDA-labeled cells from the different labeling points revealed that $\mathrm{TH}$ cells that migrate within the midbrain and cells that reach the hindbrain arise from all labeled regions, and that the latter are generated in larger numbers from regions in the ventral alar plate (Figures 2K,L). Moreover, we observed that the dorsal intermediate and ventral anterior regions gave rise to the largest number of labeled cells that lack $\mathrm{TH}$ expression. In contrast, CFDA-injections in the pretectum and in the anterior and dorsal end of the midbrain revealed that no migratory cells emanate from these regions (not shown, DI indicated in Figures 2K,L).

Hence, these studies revealed a population of TH-positive cells that descends migrating $(\mathrm{dm}-\mathrm{TH})$ following a tangential pathway along the ventral region of the alar plate of the midbrain and traverse the MHB into the hindbrain (summary diagram in Figure $2 \mathbf{K}$ ). It is important to note the detection of the additional population lacking $\mathrm{TH}$ that migrates along a similar descending route within the midbrain which did not reveal migration into the hindbrain (Figure 2L).

\section{Midbrain Descending Migratory TH Cells Converge at a Region Adjacent to the Prospective Locus Coeruleus in the Hindbrain}

Since we observed that $\mathrm{dm}-\mathrm{TH}$ cells migrated to $\mathrm{r} 1$ in the vicinity of the developing LC, we performed immunostaining for a marker for the latter, namely, the NA marker $\mathrm{DBH}$, together with the reference staining for $\mathrm{TH}$ (Figure 3). From E11 to E12, this staining revealed the $\mathrm{TH}^{+} / \mathrm{DBH}^{-} \mathrm{dm}-\mathrm{TH}$ cells in midbrain and isthmic regions and $\mathrm{TH}^{+} / \mathrm{DBH}^{+}$cells of the prospective $\mathrm{LC}$ at the anterior region of $\mathrm{r} 1$. At E11 and E11.5, $\mathrm{TH}^{+} / \mathrm{DBH}^{+}$neurons were found in $\mathrm{r} 1$ as 


\section{TH / DBH}
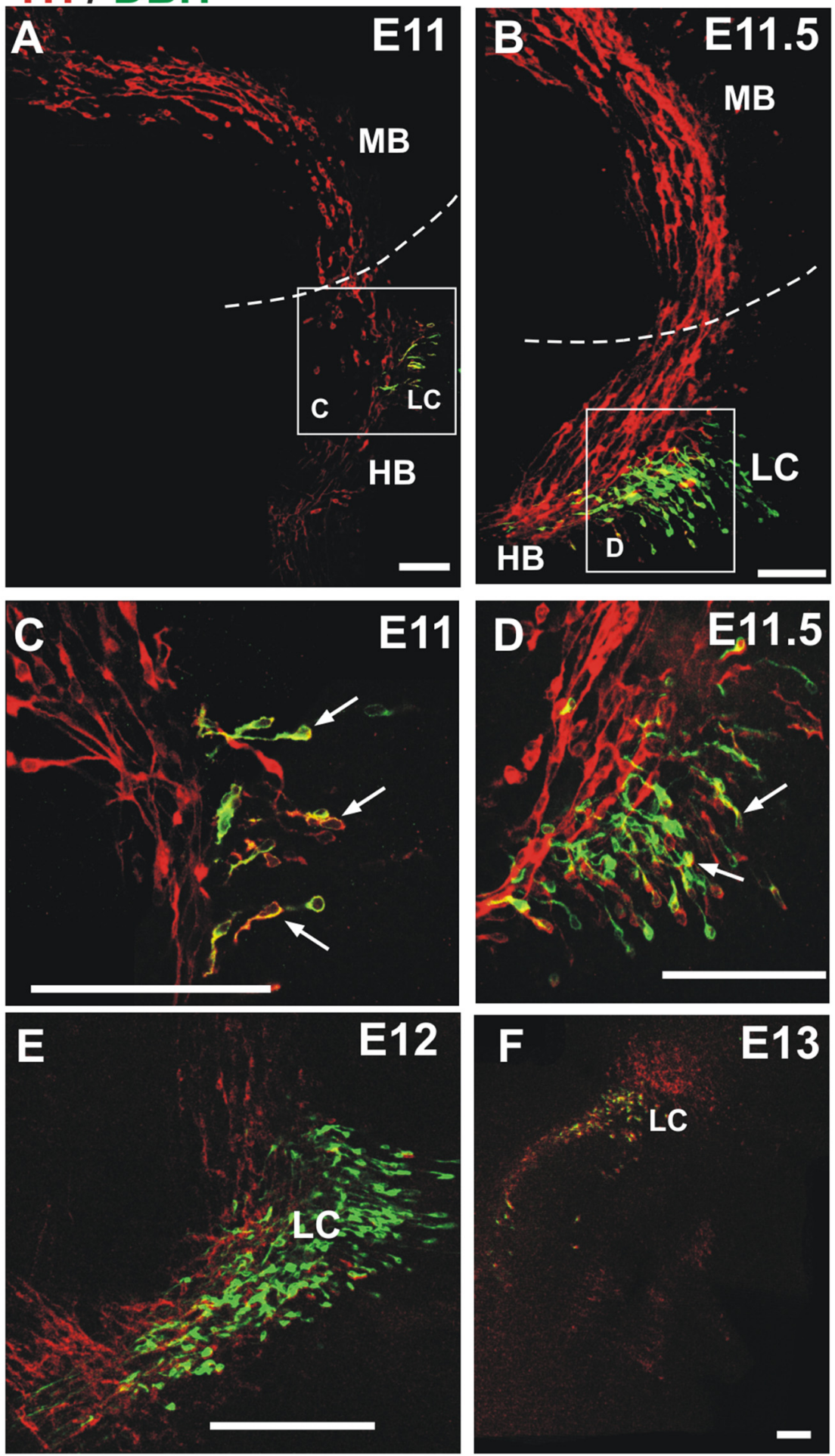

FIGURE 3 | TH migratory cells from the midbrain do not express the noradrenergic (NA) marker dopamine $\beta$-hydroxylase (DBH). Double immunostaining for TH (red) and $\mathrm{DBH}$ (green) was performed in hemibrains. In all panels, rostral is to the left and dashed lines indicate the approximate location of the MHB. Migratory cells from the midbrain (TH-only) appear to merge with $\mathrm{TH}^{+} / \mathrm{DBH}^{+}$cells (arrows) in the hindbrain at E11 and E11.5 (A-D). (C,D) Magnified views of frames indicated in (A,B), respectively; (E,F) by E12 and E13 two distinct populations (TH-only and TH/DBH double labeled cells) are detected at the rostral end of the hindbrain. Scale bars: $100 \mu \mathrm{m}$. 

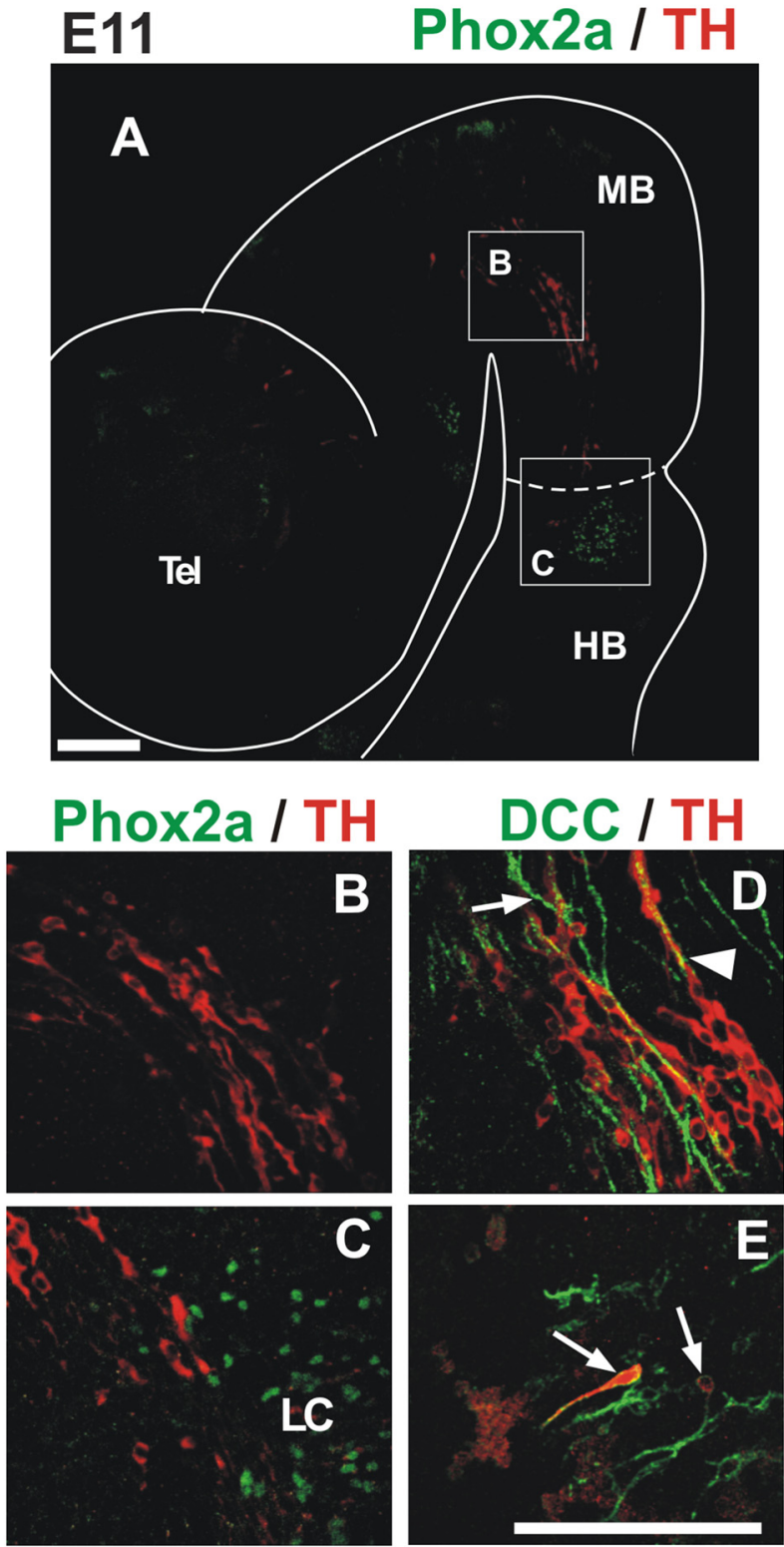

FIGURE 4 | TH migratory cells from the midbrain do not express the markers Phox2a and DCC present in LC cells. Double immunostaining for TH (red) and either Phox2a (A-C) or DCC (D,E) reveals that $\mathrm{TH}^{+}$migratory cells from the midbrain do not express these markers found in NA neurons at this stage. In all panels, rostral is to the left and dashed lines indicate the MHB. Note that although expression of DCC was absent from TH migratory cells (D), it stained $\mathrm{TH}^{+}$cells of the prospective LC (arrows in (E)) and longitudinal axons in the midbrain (arrow in (D)). Arrowhead in (D) indicates apposition of DCC axons and TH cells. Location of $\mathbf{( B , C )}$ is indicated in $(\mathbf{A})$. Panels $(\mathbf{D}, \mathbf{E})$ correspond to locations similar to $(\mathbf{B}, \mathbf{C})$, respectively. LC, locus coeruleus. Scale bars: $100 \mu \mathrm{m}$. Bar in (E) also applies to (B-D).

previously described (Aroca et al., 2006) and perpendicular to the dm-TH (Figures 3A-D). Later, at E12, a discrete $\mathrm{TH}^{+} / \mathrm{DBH}^{-}$population was detected in the hindbrain, adjacent to $\mathrm{LC} \mathrm{TH}^{+} / \mathrm{DBH}^{+}$neurons which were also present at E13 (Figures 3E,F).
To characterize further the migratory cells, we performed double staining for $\mathrm{TH}$ and Phox2a or DCC (Figure 4), two additional markers that have been shown to label NA LC neurons (Morin et al., 1997; Shi et al., 2008). DCC label was detected in longitudinal axons of the midbrain (Figure 4D, arrow) but no labeling of dm-TH cells by DCC or Phox2a was observed in this region. Some TH cells, however, were apposed to the DCC axons which, based on their location, appear to correspond to the fibers of the TmesV (Figure 4D, arrowhead; Easter et al., 1993; Mastick and Easter, 1996). Additionally, as expected by the previous evidence, both markers were found in the region containing the developing LC (Figures 4A,C,E). Hence, these results show that dm-TH cells do not express NA markers during their migration within de midbrain or into the anterior region of $\mathrm{r} 1$.

To determine whether the $\mathrm{dm}-\mathrm{TH}$ cells retain expression of markers of their region of origin as they migrate into the hindbrain, we performed double immunostaining for $\mathrm{TH}$ and the transcription factor Otx2 which is expressed in the midbrain and not in the hindbrain (Figures 5A-E). We observed that Otx2 is restricted to the forebrain and midbrain at E11 with a clear caudal limit of expression at the MHB (Figure 5A) as expected from previous studies (Li and Joyner, 2001; Inoue et al., 2012). We observed that dm-TH cells in the midbrain co-express Otx2 (Figures 5C-E, arrows) and that this expression decreases gradually as these cells get closer to the $\mathrm{MHB}$, being completely absent in the hindbrain (Figure 5E, arrowheads). To confirm this down-regulation of Otx2 in migratory cells, we performed CFDA labeling in cultured embryos followed by Otx 2 immunostaining. We confirmed that Otx2 is expressed in $\mathrm{TH}$ cells in the midbrain of unlabeled cultured embryos (Figure 5F, arrows) and that this expression decreases in CFDA labeled cells as they approach the MHB to disappear once the cells cross into the hindbrain (Figures 5G, H).

These findings indicate that $\mathrm{dm}$ - $\mathrm{TH}$ cells express Otx2 at their place of origin in the midbrain but lose this expression as they migrate into the hindbrain.

\section{Descending Migratory TH Neurons Navigate in Close Apposition to TmesV Axons}

Since we found dm-TH cells apposed to longitudinal fibers expressing DCC in the midbrain (Figure 4D), we asked whether there was a neurophilic or axonophilic interaction of $\mathrm{TH}^{+}$cells with longitudinal axon fibers. To answer this, we double-stained E11-11.5 brains for TH and the axon marker $\beta$-III tubulin. We observed that $\mathrm{TH}^{+}$cells express $\beta$-III tubulin, thus revealing their neuronal identity (Moody et al., 1989), and that they were juxtaposed to the $\beta$-III tubulin-only axons of the TmesV (Figure 6; Mastick and Easter, 1996). Higher magnification views show that all $\mathrm{TH}^{+}$cells detected were in close apposition to axon bundles along the whole longitudinal extent of the $\mathrm{dm}$-TH stream (Figures 6B,D-F). The apposition of TH neurons to axon bundles was confirmed by orthogonal digital sections (Figures 6F,F'F") and in histological sections immunostained for $\mathrm{TH}$ and $\beta$-III tubulin (Figures 6G,H). 

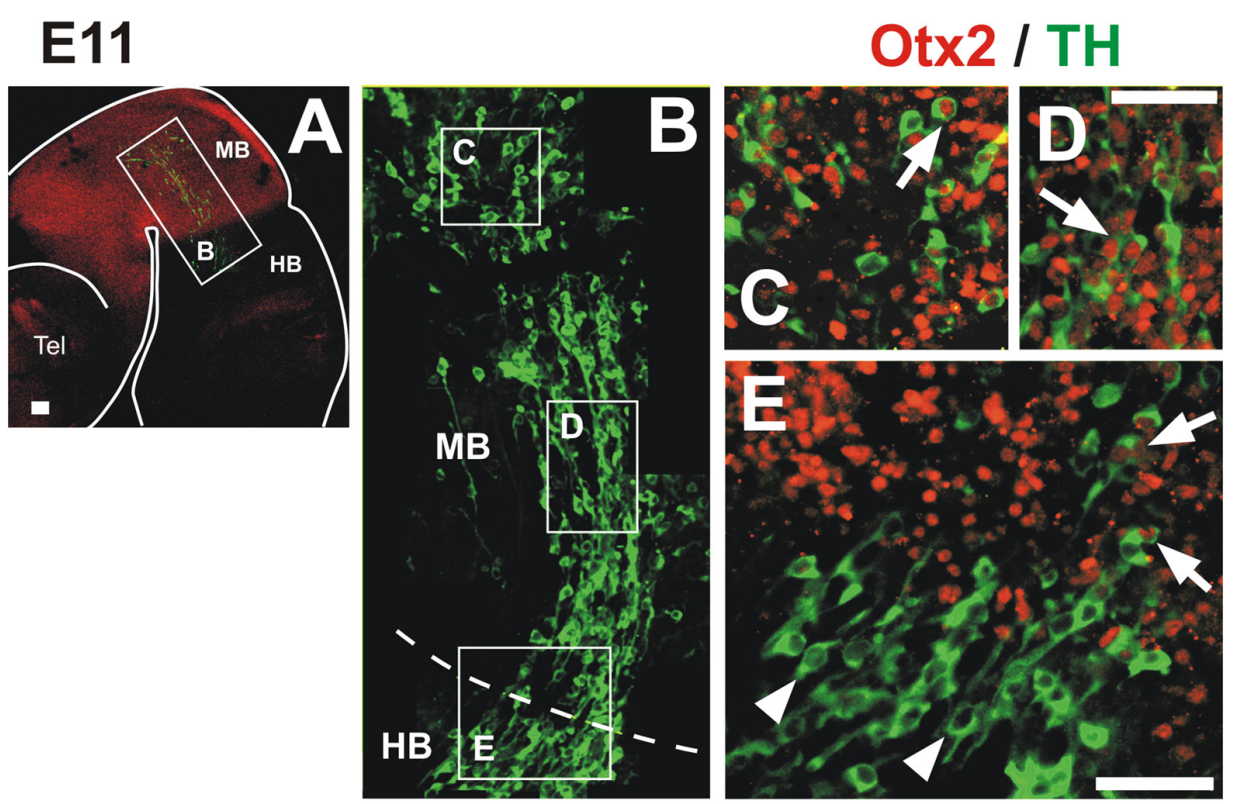

\section{E11+24hrs in culture}

Otx2 / CFDA
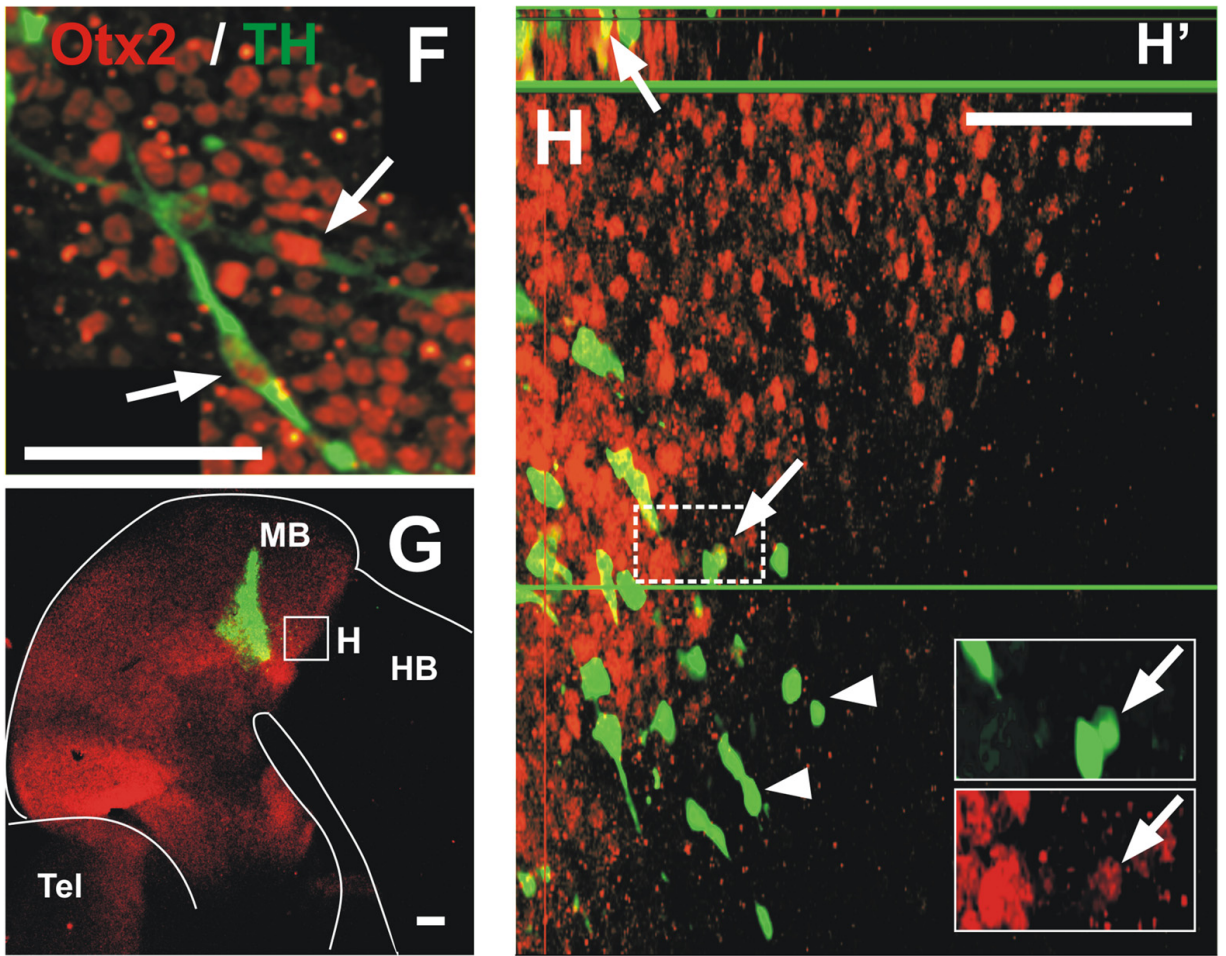

FIGURE 5 | Migratory $\mathrm{TH}^{+}$cells from the midbrain down-regulate Otx2 expression along their pathway into the hindbrain. In all panels, rostral is to the left and dashed lines indicate the MHB. (A,B) Double immunostaining of Otx2 (red) and TH (green) reveals co-expression in the midbrain; a mosaic reconstruction of individual micrographs of the whole extent of the TH cell cluster is shown in (B), its location is indicated in (A). (C-E). Magnified views of the regions indicated in (B) showing Ot×2 and TH co-expression (arrows). Panels (C,D) correspond to regions within the midbrain and (E) corresponds to the MHB region and shows lack of expression of Otx2 in TH cells in the hindbrain territory (arrowheads). Panel (F) corresponds to a location similar to (D) of an E11 rat embryo cultured for $24 \mathrm{~h}$; it shows Ot×2 and TH co-expression (arrows). (G,H) CFDA labeling (green) followed by culture and Otx2 immunostaining (red). (H) Magnified view of the region indicated in (G) showing CFDA labeled cells expressing Otx2 in the midbrain territory (arrows) and lack of expression in the hindbrain territory (arrowheads). Insets in (H) represent magnified views of the cells in the dashed white frame showing green and red channels; arrow indicates CFDA-labeled cell (green) that expresses Otx2 (red). Panel $\left(\mathbf{H}^{\prime}\right)$ shows digital orthogonal projection of plane indicated by green horizontal line showing CFDA-labeled cell that expresses Otx2 (arrow). Scale bars: $100 \mu \mathrm{m}$. Bar in (D) also applies to (C) 


\section{TH / $\beta$-III Tubulin}
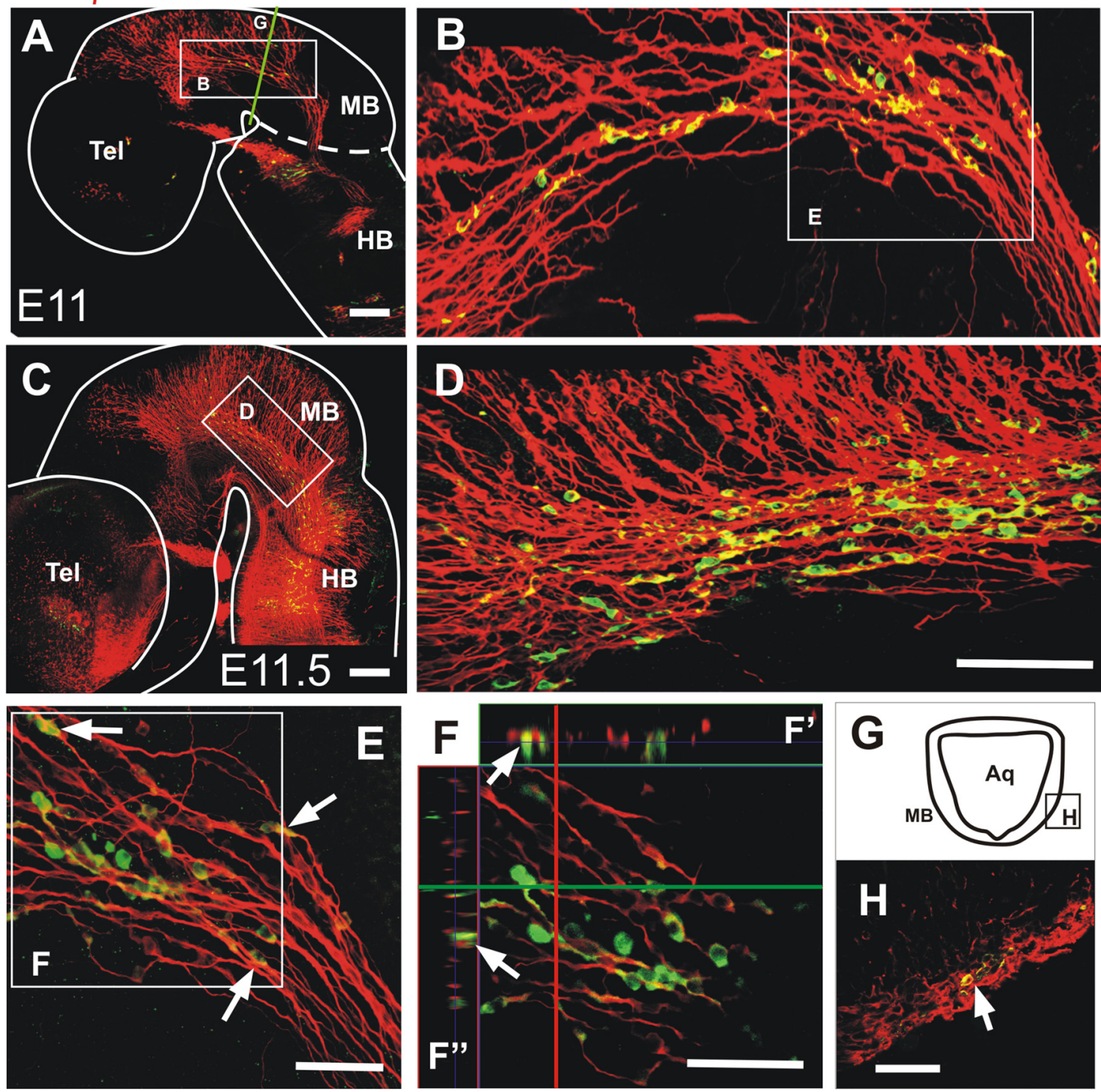

Dx-Alexa488 / TH
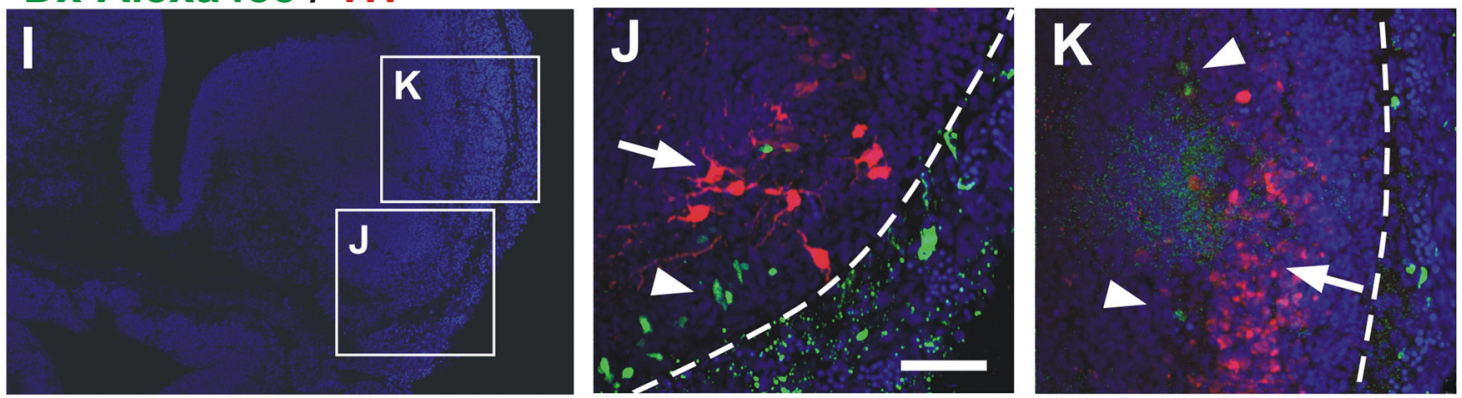

FIGURE 6 | Midbrain $\mathrm{TH}^{+}$neurons migrate in close apposition to axons of the mesencephalic trigeminal nucleus (TmesV). Double immunostaining for TH (green) and $\beta$-III tubulin (red) confirms the neuronal identity of TH-expressing cells in the midbrain alar plate and reveals their close apposition to TmesV axons along their migratory route at E11 (A,B,E,F,H) and E11.5 (C,D). (B,D) Magnifications of the regions indicated by frames in (A,C), respectively. Panel (E) is a higher magnification image of the region indicated in (B) and shows TH cells apposed to axons (arrows). (F) Single frame of a confocal Z-series from the image shown in (E), indicating with the green horizontal line and the red vertical line the position of the digital sections on the orthogonal projection of the Z-series shown on $\left(\mathbf{F}^{\prime}, \mathbf{F}^{\prime \prime}\right)$, respectively, and confirming the close apposition of TH neurons to TmesV axons. $\mathbf{( H )}$ Transverse section of the midbrain at E11 (its approximate location is indicated by frame in 


\section{FIGURE 6 | Continued}

(G) and by the green line in (A)), showing double immunostaining for $\mathrm{TH}$ and $\beta$-III tubulin indicating that TH neurons are surrounded by axon bundles of the TmesV (arrow). (I-K) TmesV neurons were labeled from the trigeminal ganglion in rat embryos (E12.5 + 6 h) do not express TH. Embryos of E12.5+ $6 \mathrm{~h}$ were labeled from the trigeminal ganglion with Dextran Alexa Fluor 488 (green) followed by TH immunostaining (red). Panel (l) shows a panoramic view of a transverse section at the anterior end of $r 1$ and the location of (J) and (K). Arrow in (J) indicates the developing LC and arrowhead indicates labeled TmesV cells. Arrow in (K) indicates a lateral cluster of cells that is continuous with the TH expressing territory in the ventral rim of the alar plate in the midbrain and arrowheads indicate labeled TmesV cells. Dotted lines indicate the exterior boundary of the developing brainstem. Scale bars: (A-H) $100 \mu \mathrm{m}$. Bar in (D) also applies to (B). (J,K) $50 \mu \mathrm{m}$.

To assess further the proximity of the ventral alar plate $\mathrm{TH}$ domain to the TmesV, we performed retrograde labeling from the trigeminal ganglion in rat embryos with DextranAlexa488 and immunostaining for TH (Figures 6I-K). This allowed the labeling of the earliest projecting TmesV neurons at the anterior region of $\mathrm{r} 1$ at E12.5 plus 6 h (green, Figures 6J,K, arrowheads). Immunostaining with $\mathrm{TH}$ antibodies (red) revealed a population which by its ventrolateral location seems to correspond to the prospective LC (Figure 6J, arrow) and a faintly stained dorsolateral population (Figure 6K, arrow) at the ventral region of the alar plate. Retrogradely labeled TmesV neurons were found adjacent to both TH cell groups; external to the ventral group and internal to the dorsal group. Hence, these results confirm the proximity of the dorsal $\mathrm{TH}$ cell cluster to TmesV neurons which were found to lack $\mathrm{TH}$ expression.

As DCC is expressed by TmesV axons (Figure 4D), we hypothesized that this Netrin 1 receptor has a role in TmesV axon guidance, and indirectly, in $\mathrm{dm}-\mathrm{TH}$ migration. To test this idea, we interfered with DCC function in cultured E11 embryos with the aim of disrupting TmesV axon projection and assessing its effects in the dm-TH cells. For this we used a chimeric protein containing the DCC ectodomain fused to the immunoglobulin Fc domain (DCC-Fc) in cultured embryos. Control cultures with and without Ig-Fc molecules stained for $\mathrm{TH}$ and $\beta$-III tubulin, revealed normal distribution of Tmes $\mathrm{V}$ axons and $\mathrm{dm}-\mathrm{TH}$ neurons apposed to them as in non-cultured wildtype E11.5 embryos (Figures $\mathbf{7 A}, \mathbf{C}, \mathbf{D}, \mathbf{D}^{\prime}, \mathbf{D}^{\prime \prime}$ ). In contrast, in all nine embryos cultured with DCC-Fc (Figures $7 \mathbf{B}, \mathbf{C}$ ), the normal appearance of Tmes $\mathrm{V}$ axons was drastically altered; the longitudinal axon bundles were greatly reduced, disorganized and discontinuous (arrowhead), and in most cultures failed altogether to reach the hindbrain (white arrow). Quantitation of the overall axon bundle density in the ventral alar plate region containing the $\mathrm{TH}$ cell population revealed a drastic reduction in Fc-DCC treated embryos compared to control clutures (Figure $7 \mathbf{H}$ ). Concomitantly, the normal longitudinal alignment and distribution of $\mathrm{dm}-\mathrm{TH}$ neurons was dramatically affected, and irregular clusters of these cells were observed (Figure 7B). It is important to note that most $\mathrm{TH}$ neurons remained closely associated to TmesV axons ( 9 embryos, Figure $7 \mathbf{B}$ and Figures $\mathbf{7 E}, \mathbf{E}^{\prime}, \mathbf{E}^{\prime \prime}$ ) while some $\mathrm{TH}$ neurons dissociated from axons in 3 out of 9 embryos (Figure $7 \mathbf{B}$, green arrows). Overall, our findings suggest that $\mathrm{dm}$-TH neurons depend on Tmes $\mathrm{V}$ axons for their arrangement and descending migration.

Seeking confirmation of a role of DCC on TmesV axon projection, we analyzed wild-type and DCC knockout mouse embryos. We observed that by E9.5, axons in five wild-type embryos have reached the hindbrain, displaying a similar distribution to that observed in E11 rat embryos (Figure 7F), in agreement with the known developmental time difference between these two rodent species. In all five $\mathrm{DCC}^{-/-}$embryos analyzed, however, axons in the anterior midbrain misprojected rostrally and ventrally (arrow, Figure 7G) and throughout its longitudinal extent, the Tmes $\mathrm{V}$ axon bundle was dorsally displaced (arrowheads, Figures 7G,I). Hence, these results confirm a role for DCC in TmesV axon projection.

\section{Descending Migratory Cells Expressing Calbindin in the Embryonic Mouse Midbrain}

In an attempt to identify the dm- $\mathrm{TH}$ in mouse embryos, we performed $\mathrm{TH}$ immunstaining as described for rat embryos. Analysis of E9-E10.5 mouse embryos, allowing for the developmental time difference between rat and mouse, revealed only at E9.5 a transient low TH expression at the dorsal-most aspect of the midbrain near its boundary with the pretectum (Figure 8A). A migratory TH population equivalent to that found in rat embryos, however, was not detected. In contrast, a small population of cells expressing the neuronal marker calbindin was found in the E9.5 mouse embryonic midbrain displaying a similar longitudinal distribution as $\mathrm{dm}-\mathrm{TH}$ cells that was also apposed to TmesV axons (Figures 8B-D). Moreover, CFDA labeling in the midbrain of E9.5 mouse embryos followed by culture, revealed posteriorly migrating cells within the midbrain, some of which were calbindin-positive (Figures 8E-G). A similar calbindin population was found intermingled with $\mathrm{TH}$ cells in the midbrain of E10.5 rat embryos but these cells were not detected among the cells that migrate within the midbrain or into the hindbrain in cultured embryos upon CFDA labeling (Figures 8H,I and data not shown).

These findings confirm the existence of descending migratory cells within the mouse midbrain that also interact with TmesV axons but that differ in identity from those observed in rat embryos at equivalent stages.

\section{DISCUSSION}

In this study, we have uncovered a novel population of neurons expressing $\mathrm{TH}$ that migrates from the alar plate of the midbrain to the anterior region of the hindbrain in E10.5 to E11.5 rat embryos.

Labeling of these neurons with the fluorescent tracer CFDA in cultured embryos, revealed their origin at the whole longitudinal and dorsoventral extent of the midbrain alar plate region that also gives rise to the neurons of the TmesV (Mastick and Easter, 1996). 


\section{E11 rat +24 hours in culture TH / $\beta-$ III Tubulin}
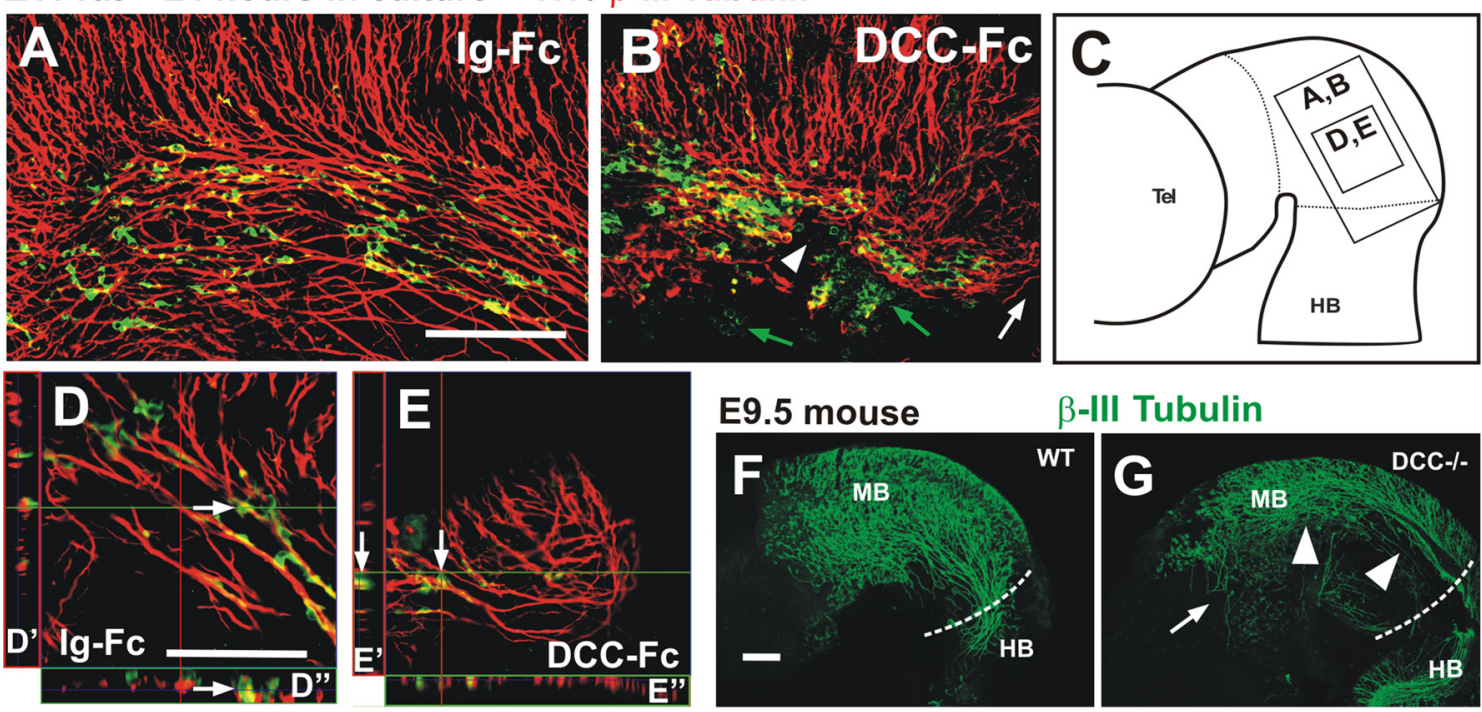

E9.5 mouse

\section{$\beta$-III Tubulin}
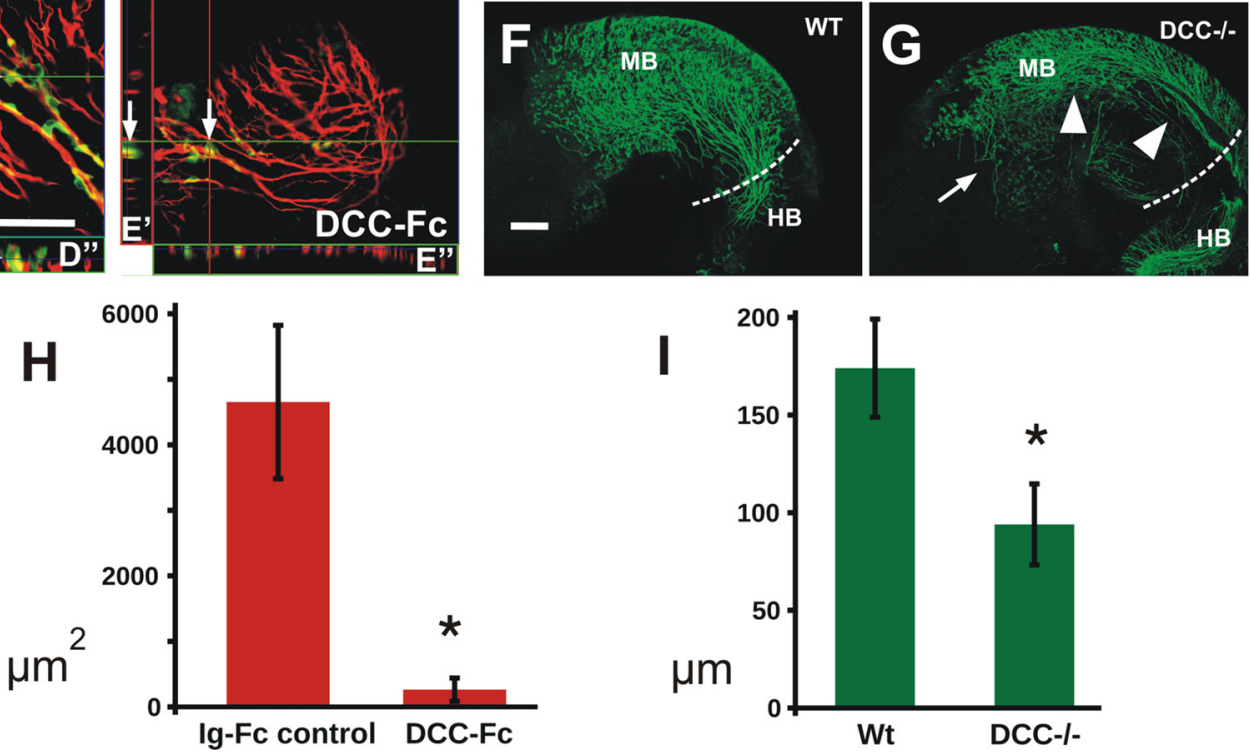

FIGURE 7 | Blocking DCC signaling in rat embryos impairs TmesV axon projection and TH cell migration, and TmesV axons misproject in DCC mutant mouse embryos. Embryos cultured in presence of Ig-Fc as control (A,D) or with the DCC-Fc chimera to alter TmesV axon projection (B,E) followed by double immunostaining for $\mathrm{TH}$ and $\beta$-III tubulin; their approximate location is indicated in diagram in (C). Overall organization of TmesV neurons and their axon projection was dramatically altered by DCC-FC (B,E) along with a drastic disorganization of TH neurons and their impaired caudal migration into the hindbrain. White arrows in $(\mathbf{D}, \mathbf{E})$ indicate $\mathrm{TH}^{+}$cells apposed to $\beta$-III tubulin axons in single optical sections and orthogonal digital projections ( $\mathbf{D}^{\prime}, \mathbf{D}^{\prime \prime}$ and $\mathbf{E}^{\prime}, \mathbf{E}^{\prime \prime}$ respectively); in (B) green arrows indicate $\mathrm{TH}^{+}$cells that do not interact with $\beta$-III tubulin axons, white arrowhead indicates interruption of the longitudinal tract of the TmesV, and white arrow indicates lack of projection of the TmesV into the hindbrain. Panel (F) is a flat-mounted hemibrain of a wild-type mouse embryo stained for $\beta$-III tubulin and (G) is from a $\mathrm{DCC}^{-/-}$embryo. Arrow in (G) indicates misprojecting axons and arrowheads indicate dorsal displacement of the TmesV axon bundle. (H) The treatment with DCC-Fc reduced the density of TmesV axon bundles. The area covered by $\beta$-III tubulin axon bundles in projections of confocal Z-stacks was measured. Asterisk indicates statistical difference between controls and DCC-Fc treated embryos (Wilcoxon-Mann-Whitney test, $p=0.0143$ ). (I) The TmesV axon bundle was dorsally displaced in $\mathrm{DCC}^{-/-}$embryos. The distance of the center of the axon bundle from the dorsal edge of the brain was measured at the isthmic region for wild-type and mutant embryos. Dorsal displacement is revealed by a significantly shorter distance of the bundle in mutant embryos. Asterisk indicates statistical difference between controls and $\mathrm{DCC}^{-/-}$embryos (Wilcoxon-Mann-Whitney test, $\left.p=0.008\right)$. Scale bar: $100 \mu \mathrm{m}$. Bars in (A,D,F) also apply to (B,E,G), respectively.

We also observed that the migratory cells converge into the alar plate ventral rim, in close apposition to the $\beta$-III tubulinpositive bundles of the descending TmesV axons (Mastick and Easter, 1996). Some neurons from this population ( $\mathrm{dm}-\mathrm{TH})$, were seen to reach the anterior end of $\mathrm{r} 1$ in the hindbrain, in the vicinity of NA neurons of the prospective LC (Aroca et al., 2006). Their distinct midbrain origin was confirmed by labeling with ventricular injections in this territory, by their early expression of Otx2, and their lack of the markers Phox2a, DBH or DCC, expressed by LC neurons (Morin et al., 1997; Shi et al., 2008). Near the MHB, however, $\mathrm{dm}-\mathrm{TH}$ neurons were observed to down-regulate Otx2 expression, presumably under the influence of this organizer region. These cells contrast with other migratory populations that have been identified following the markers of their regions of origin to apparently ectopic locations; a recent study uncovered one such population that migrates from the hypothalamus to the amygdala and retains in its final settling region the expression of Otp, a marker of their region of origin (García-Moreno et al., 2010).

The close interaction of $\mathrm{dm}$ - TH neurons with TmesV axons was revealed to be of relevance for the migratory population observed. Disrupting TmesV axon projection with a soluble version of the DCC ectodomain in cultured embryos, caused the disorganization of the $\mathrm{dm}-\mathrm{TH}$ and prevented their clustering 


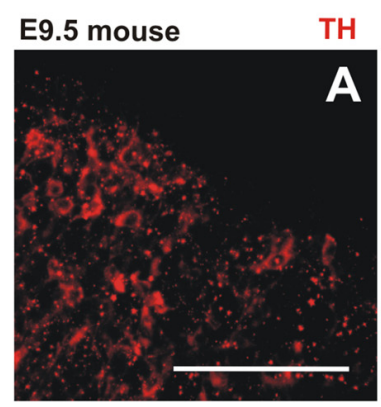

\section{E9.5 mouse}

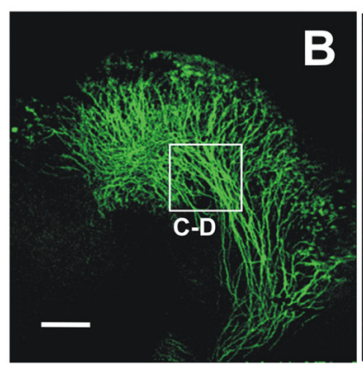

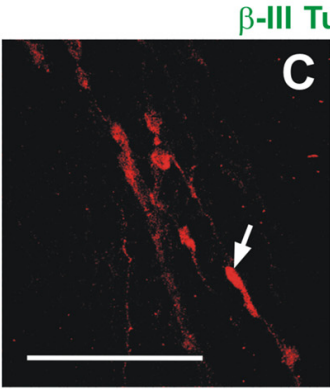

$\beta$-III Tubulin / Calbindin

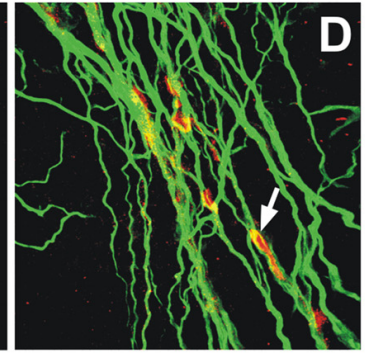

E9.5 mouse +24 hours in culture
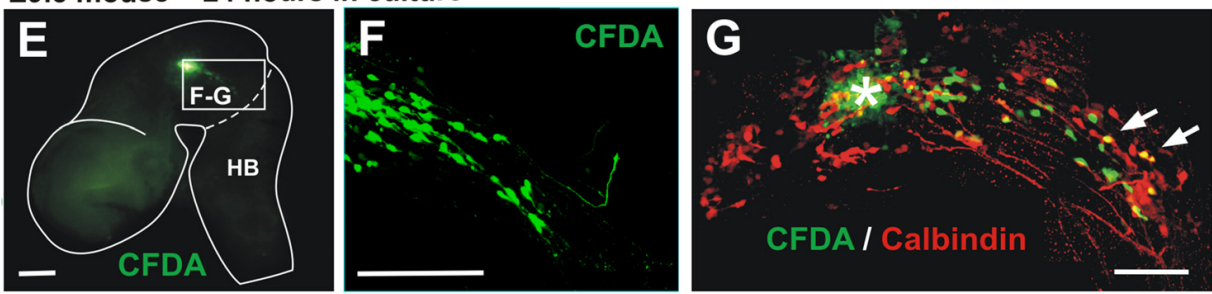

E10.5 rat

E11.5 rat +24 hours in culture
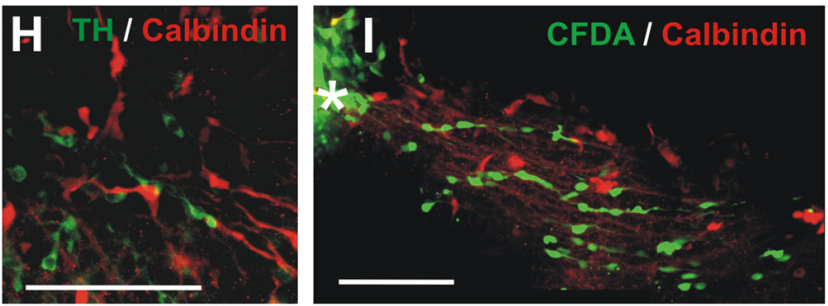

FIGURE 8 | Descending migratory population of calbindin-expressing cells in mouse embryos. (A) E9.5 mouse embryonic midbrain immunostained for TH showing a low-expressing population in the dorsal-most aspect of the midbrain near its boundary with the pretectum. (B-D) E9.5 mouse midbrain showing calbindin cells apposed to TmesV axons ( $\beta$-III tubulin). Panels (C,D) are red and merged red/green channels, respectively, of the same magnified region indicated in (B). (E,F) CFDA labeling was performed in the midbrain of E9.5 embryos followed by $24 \mathrm{~h}$ in culture revealing caudally-migrating cells. Panel $\mathbf{( F )}$ is a magnification of the frame indicated in (E). (G) Following CFDA labeling (asterisk) and culture, the midbrain was immunostained for calbindin showing that some migratory cells express this marker (arrows). (H) E10.5 rat embryonic midbrain immunostained for TH and calbindin in a location similar to (C-D). (I) CFDA labeling in the midbrain of E11.5 rat embryos followed by $24 \mathrm{~h}$ in culture and immunostaining showing caudally-migrating cells that do not express calbindin. Scale bars: $100 \mu \mathrm{m}$.

in the stream that reaches the hindbrain, thus indicating that TmesV axons are used by $\mathrm{dm}-\mathrm{TH}$ neurons as neurophilic substrate during their descending displacement. Despite the dramatic alteration on the pathfinding of TmesV axons, however, most $\mathrm{dm}$-TH neurons remained attached to them. This reveals a strong interaction, which is perhaps an important determinant of $\mathrm{dm}-\mathrm{TH}$ migration. Incidentally, our studies also uncovered a role for DCC-mediated signaling in the TmesV axon pathfinding in rat embryos, also confirmed in mouse embryos lacking DCC. Hence, our results suggest that the role of DCC in dm-TH cell migration is mostly indirect by determining the TmesV axon projection. This contrasts with the role proposed for DCC in other developing neural cell types such as DA neurons (Xu et al., 2010), oligodendrocyte precursor cells (Spassky et al., 2002), dorsal spinal interneurons (Junge et al., 2016), and cerebellar neurons (Alcántara et al., 2000) in which it appears to mediate the direct effects of the chemotropic molecule netrin1.

In our studies, we also observed in the mouse embryonic midbrain, descending migratory cells in apposition to TmesV axons. These cells, however, differed from those observed in rat embryos in their lack of TH and in that a fraction of the mouse migratory cells express calbindin, thus revealing diversity among the migrating cell populations. Calbindin-expressing cells were also detected in the rat midbrain but no migration of these cells was observed.

The dorsal midbrain in mouse embryos has been previously described to contain transiently the TH-expressing A11 cell group first observed at E12.5 (Marín et al., 2005). Since this roughly corresponds to a stage in rat embryos (E13.5) which is at least two gestational days after the rat $\mathrm{dm}-\mathrm{TH}$ population is last detected (E11.5), the equivalence between these two populations is unlikely and remains to be ascertained. It is also noteworthy that a similar population of TH-immunoreactive cells is present in the dorsal midbrain in human embryos (Puelles and Verney, 1998). Moreover, an earlier study employing a TH-lacZ transgene in mice, also described the presence of TH cells in the dorsolateral mesencephalon peaking from E9.5 to E10.5 (Son et al., 1996). An extensive search with our immunodetection approach, however, only detected a transient low $\mathrm{TH}$-expressing population in the 
dorsal E9.5 midbrain and a search of TH mRNA by in situ hybridization at those stages did not reveal TH cells (Marín et al., 2005). This suggests that their TH expression levels are low and were better detected by the signal amplification afforded by ß-galactosidase in transgenic mice (Son et al., 1996). In another study in mouse embryos, labeling at E8.5 by a Wnt-1 expressiondependent reporter system, revealed a small number of cells that migrate from the midbrain into the ventral hindbrain, some of which express the serotoninergic marker 5-HT (Zervas et al., 2004). Hence, the differences in the timing of appearance of $\mathrm{TH}$ cells in the dorsal midbrain in the various species described and the differences we observed between the rat and mouse migratory cells reveal a population complexity that requires further comparative studies.

The crossing by neurons of boundaries between distinct morphogenetic brain territories is a source of neuronal diversity involved in the completion of neuronal repertoires in diverse brain regions (García-Moreno et al., 2010; Rudolph et al., 2010). Cortical GABAergic neurons, for example, originate in the ganglionic eminences and migrate to populate the developing cortex (de Carlos et al., 1996) passing across boundaries of Wnt signals and thus contributing interneurons to the cortical plate (Quinlan et al., 2009). Similarly, the dm-TH contributes $\mathrm{TH}^{+} / \mathrm{DBH}^{-}$neurons to a cell cluster adjacent to the LC. Since our studies are limited to a narrow time window in the developing brain, further studies are necessary to determine whether the midbrain migratory neurons remain adjacent to the adult LC, as well as their fate and functional implications.

Our findings reveal a TH cell group in the dorsal midbrain of rat embryos that migrates posteriorly, with some cells reaching the vicinity of the LC well within the hindbrain. It is unlikely that these neurons are catecholaminergic or belong to the LC, however, owing to their midbrain origin and their lack of expression of Phox2a, DBH and DCC. On the other hand, the origin of these cells in the alar plate of the midbrain, their close association to TmesV axons during their migration, and the proximity to the LC of those that reach the hindbrain, suggest that these neurons are a lineage related to TmesV neurons, although their phenotypes are clearly different. The idea of the migration of midbrain TmesV neurons into the hindbrain has been previously suggested (reviewed in Lazarov, 2002). The possible projection of $\mathrm{dm}-\mathrm{TH}$ neurons along the Tmes $V$ axon pathway, however, could not be confirmed in this study as our cell migration assay is limited to a short developmental time window and no expression of the TmesV markers E1.9 and B30 was detected at these early stages (not

\section{REFERENCES}

Alcántara, S., Ruiz, M., De Castro, F., Soriano, E., and Sotelo, C. (2000). Netrin 1 acts as an attractive or as a repulsive cue for distinct migrating neurons during the development of the cerebellar system. Development 127, 1359-1372.

Aroca, P., Lorente-Cánovas, B., Mateos, F. R., and Puelles, L. (2006). Locus coeruleus neurons originate in alar rhombomere 1 and migrate into the basal plate: studies in chick and mouse embryos. J. Comp. Neurol. 496, 802-818. doi: 10.1002/cne.20957

Auclair, F., Marchand, R., and Glover, J. C. (1999). Regional patterning of reticulospinal and vestibulospinal neurons in the hindbrain of mouse shown; Stainier and Gilbert, 1989, 1990). Moreover, we observed that the earliest projecting TmesV axons do not appear to express $\mathrm{TH}$.

Hence, we describe in rat embryos a novel TH neuronal population that follows a hitherto unknown neurophilic or axonophilic migratory pathway apposed to TmesV axons within the midbrain alar plate and into the anterior region of $\mathrm{r} 1$ in the hindbrain adjacent to the prospective LC. This population, which does not share origin or identity with LC cells, seems to be related in lineage to TmesV neurons although their phenotypes are clearly different. An additional population which does not express $\mathrm{TH}$ was also detected in parallel to originate in the midbrain alar plate and to migrate caudally as well but with no evidence of migration into the hindbrain. These cell populations, along with similar descending cells but with different phenotypes in the mouse embryonic midbrain, warrant further studies to ascertain their fate, functional relevance and interspecies divergence.

\section{AUTHOR CONTRIBUTIONS}

CG-P, ET and AV-E conceived the project and designed the experiments. CG-P, DÁ-G, AM and CL-F performed the experiments and analyzed the data. GSM designed the experiments and interpreted results. CG-P, AM and AV-E wrote the article. AV-E and ET supervised the project.

\section{FUNDING}

The support for these studies was obtained from Consejo Nacional de Ciencia y Tecnología (CONACYT; 293439). Funding was also provided by The COBRE Center for Neuroplasticity, NIH NIGMS GM103642 (to AM).

\section{ACKNOWLEDGMENTS}

For technical support we thank Laura Gonzalez, Martín García Servín, Minkyung Kim, Alejandra Castilla, Alberto Lara, Omar González, Sandra Hernández, Ramón Martínez, Nidia Hernández and Adrián Oskam. This work was also supported by Luis Aguilar, Alejandro de León, Jair García and Carlos S. Flores of the National Laboratory for Scientific Visualization (Laboratorio Nacional de Visualización Científica Avanzada, LAVIS, www.lavis.mx).

and rat embryos. J. Comp. Neurol. 411, 288-300. doi: 10.1002/(sici)10969861(19990823)411:2<288::aid-cne9>3.0.co;2-u

Bertram, I., Bernstein, H.-G., Lendeckel, U., Bukowska, A., Doborwolny, H., Keilhoff, G., et al. (2007). Immunohistochemical evidence for impaired neuregulin-1 signaling in the prefrontal cortex in schizophrenia and in unipolar depression. Ann. N Y Acad. Sci. 1096, 147-156. doi: 10.1196/annals. 1397.080

Bodea, G. O., Spille, J.-H., Abe, P., Andersson, A. S., Acker-Palmer, A., Stumm, R., et al. (2014). Reelin and CXCL12 regulate distinct migratory behaviors during the development of the dopaminergic system. Development 141, 661-673. doi: 10.1242/dev.099937 
Chinta, S. J., and Andersen, J. K. (2005). Dopaminergic neurons. Int. J. Biochem. Cell Biol. 37, 942-946. doi: 10.1016/j.biocel.2004.09.009

Chuang, H. C., Huang, T. N., and Hsueh, Y. P. (2015). T-Brain-1-a potential master regulator in autism spectrum disorders. Autism Res. 8, 412-426. doi: 10.1002 /aur. 1456

Czajkowsky, D. M., Hu, J., Shao, Z., and Pleass, R. J. (2012). Fc-fusion proteins: new developments and future perspectives. EMBO Mol. Med. 4, 1015-1028. doi: 10.1002/emmm.201201379

de Carlos, J. A., López-Mascaraque, L., and Valverde, F. (1996). Dynamics of cell migration from the lateral ganglionic eminence in the rat. J. Neurosci. 16, 6146-6156. doi: 10.1523/jneurosci.16-19-06146.1996

Easter, S. S., Ross, L. S., and Frankfurter, A. (1993). Initial tract formation in the mouse brain. J. Neurosci. 13, 285-299. doi: 10.1523/jneurosci.13-01-00285.1993

Fazeli, A., Dickinson, S. L., Hermiston, M. L., Tighe, R. V., Steen, R. G., Small, C. G., et al. (1997). Phenotype of mice lacking functional deleted in colorectal cancer (Dec) gene. Nature 386, 796-804. doi: 10.1038/38 $6796 \mathrm{a} 0$

García-Moreno, F., Pedraza, M., Di Giovannantonio, L. G., Di Salvio, M., LópezMascaraque, L., Simeone, A., et al. (2010). A neuronal migratory pathway crossing from diencephalon to telencephalon populates amygdala nuclei. Nat. Neurosci. 13, 680-689. doi: 10.1038/nn.2556

García-Peña, C. M., Kim, M., Frade-Pérez, D., Ávila-González, D., Téllez, E., Mastick, G. S., et al. (2014). Ascending midbrain dopaminergic axons require descending GAD65 axon fascicles for normal pathfinding. Front. Neuroanat. 8:43. doi: $10.3389 /$ fnana.2014.00043

Ghashghaei, H. T., Lai, C., and Anton, E. S. (2007). Neuronal migration in the adult brain: are we there yet? Nat. Rev. Neurosci. 8, 141-151. doi: 10.1038/ nrn2074

Goossens, D., Van Gestel, S., Claes, S., De Rijk, P., Souery, D., Massat, I., et al. (2003). A novel CpG-associated brain-expressed candidate gene for chromosome 18q-linked bipolar disorder. Mol. Psychiatry 8, 83-89. doi: $10.1038 /$ s.mp. 4001190

Inoue, F., Kurokawa, D., Takahashi, M., and Aizawa, S. (2012). Gbx2 directly restricts Otx2 expression to forebrain and midbrain, competing with class III POU factors. Mol. Cell. Biol. 32, 2618-2627. doi: 10.1128/mcb.00083-12

Joyner, A. L., Liu, A., and Millet, S. (2000). Otx2, Gbx2 and Fgf8 interact to position and maintain a mid-hindbrain organizer. Curr. Opin. Cell Biol. 12, 736-741. doi: 10.1016/s0955-0674(00)00161-7

Junge, H. J., Yung, A. R., Goodrich, L. V., and Chen, Z. (2016). Netrin1/DCC signaling promotes neuronal migration in the dorsal spinal cord. Neural Dev. 11:19. doi: 10.1186/s13064-016-0074-x

Lahti, L., Achim, K., and Partanen, J. (2013). Molecular regulation of GABAergic neuron differentiation and diversity in the developing midbrain. Acta Physiol. 207, 616-627. doi: 10.1111/apha.12062

Lazarov, N. E. (2002). Comparative analysis of the chemical neuroanatomy of the mammalian trigeminal ganglion and mesencephalic trigeminal nucleus. Prog. Neurobiol. 66, 19-59. doi: 10.1016/s0301-0082(01)00021-1

Lencz, T., Guha, S., Liu, C., Rosenfeld, J., Mukherjee, S., DeRosse, P., et al. (2013). Genome-wide association study implicates NDST3 in schizophrenia and bipolar disorder. Nat. Commun. 4:2739. doi: 10.1038/ncomms3739

Letinic, K., and Rakic, P. (2001). Telencephalic origin of human thalamic GABAergic neurons. Nat. Neurosci. 4, 931-936. doi: 10.1038/nn0901-931

Li, J. Y., and Joyner, A. L. (2001). Otx2 and Gbx2 are required for refinement and not induction of mid-hindbrain gene expression. Development 128, 4979-4991.

Li, J., Liu, J., Feng, G., Li, T., Zhao, Q., Li, Y., et al. (2011). The MDGA1 gene confers risk to schizophrenia and bipolar disorder. Schizophr. Res. 125, 194-200. doi: 10.1016/j.schres.2010.11.002

Liu, S., Liu, W. T., Liu, Y. P., Dong, H. L., Henkemeyer, M., Xiong, L. Z., et al. (2011). Blocking EphB1 receptor forward signaling in spinal cord relieves bone cancer pain and rescues analgesic effect of morphine treatment in rodents. Cancer Res. 71, 4392-4402. doi: 10.1158/0008-5472.can-10-3870

Marín, F., Herrero, M. T., Vyas, S., and Puelles, L. (2005). Ontogeny of tyrosine hydroxylase mRNA expression in mid- and forebrain: neuromeric pattern and novel positive regions. Dev. Dyn. 234, 709-717. doi: 10.1002/dvdy. 20467

Marín, O., and Rubenstein, J. L. R. (2003). Cell migration in the forebrain. Annu. Rev. Neurosci. 26, 441-483. doi: 10.1146/annurev.neuro.26.041002. 131058
Marx, A., Backes, C., Meese, E., Lenhof, H. P., and Keller, A. (2016). EDISONWMW: exact dynamic programing solution of the wilcoxon-mann-whitney test. Genomics Proteomics Bioinformatics 14, 55-61. doi: 10.1016/j.gpb.2015. 11.004

Mastick, G. S., and Easter, S. S. (1996). Initial organization of neurons and tracts in the embryonic mouse fore- and midbrain. Dev. Biol. 173, 79-94. doi: 10.1006/dbio.1996.0008

Miquelajáuregui, A., Varela-Echavarria, A., Ceci, M. L., García-Moreno, F., Ricano, I., Hoang, K., et al. (2010). LIM-homeobox gene Lhx5 is required for normal development of Cajal-Retzius cells. J. Neurosci. 30, 10551-10562. doi: 10.1523/JNEUROSCI.5563-09.2010

Moody, S., Quigg, M., and Frankfurter, A. (1989). Development of the peripheral trigeminal system in the chick revealed by an monoclonal antibody. J. Comp. Neurol. 279, 567-580. doi: 10.1002/cne.902790406

Morin, X., Cremer, H., Hirsch, M. R., Kapur, R. P., Goridis, C., and Brunet, J. F. (1997). Defects in sensory and autonomic ganglia and absence of locus coeruleus in mice deficient for the homeobox gene Phox2a. Neuron 18, 411-423. doi: 10.1016/s0896-6273(00)81242-8

Nadarajah, B., and Parnavelas, J. G. (2002). Modes of neuronal migration in the developing cerebral cortex. Nat. Rev. Neurosci. 3, 423-432. doi: 10.1038/ nrn845

Prakash, N., Brodski, C., Naserke, T., Puelles, E., Gogoi, R., Hall, A., et al. (2006). A Wnt1-regulated genetic network controls the identity and fate of midbraindopaminergic progenitors in vivo. Development 133, 89-98. doi: 10.1242/dev. 02181

Prakash, N., and Wurst, W. (2006). Development of dopaminergic neurons in the mammalian brain. Cell. Mol. Life Sci. 63, 187-206. doi: 10.1007/s00018-0055387-6

Puelles, L., and Verney, C. (1998). Early neuromeric distribution of tyrosinehydroxylase- immunoreactive neurons in human embryos. J. Comp. Neurol. 394, 283-308. doi: 10.1002/(sici)1096-9861(19980511)394:3<283::aid-cne2>3. $0 . \operatorname{co} ; 2-y$

Quinlan, R., Graf, M., Mason, I., Lumsden, A., and Kiecker, C. (2009). Complex and dynamic patterns of Wnt pathway gene expression in the developing chick forebrain. Neural Dev. 4:35. doi: 10.1186/1749-8104-4-35

Rakic, P. (1971). Neuron-glia relationship during granule cell migration in developing cerebellar cortex: a Golgi and electron microscopic study in Maccacus rhesus. J. Comp. Neurol. 141, 282-312. doi: 10.1002/cne.9014 10303

Rakic, P. (1990). Principles of neural cell migration. Experientia 46, 882-891. doi: $10.1007 / \mathrm{bf} 01939380$

Rakić, S., Kanatani, S., Hunt, D., Faux, C., Cariboni, A., Chiara, F., et al. (2015). Cdk5 phosphorylation of ErbB4 is required for tangential migration of cortical interneurons. Cereb. Cortex 25, 991-1003. doi: 10.1093/cercor/ bht 290

Reuter, M. S., Musante, L., Hu, H., Diederich, S., Sticht, H., Ekici, A. B., et al. (2014). NDST1 missense mutations in autosomal recessive intellectual disability. Am. J. Med. Genet. A 164, 2753-2763. doi: 10.1002/ajmg.a. 36723

Rudolph, J., Zimmer, G., Steinecke, A., Barchmann, S., and Bolz, J. (2010). Ephrins guide migrating cortical interneurons in the basal telencephalon. Cell Adhes. Migr. 4, 400-408. doi: 10.4161/cam.4.3.11640

Shi, M., Guo, C., Dai, J. X., and Ding, Y. Q. (2008). DCC is required for the tangential migration of noradrenergic neurons in locus coeruleus of mouse brain. Mol. Cell. Neurosci. 39, 529-538. doi: 10.1016/j.mcn.2008. 07.023

Simon, H. H., Saueressig, H., Wurst, W., Goulding, M. D., and O'Leary, D. D. (2001). Fate of midbrain dopaminergic neurons controlled by the engrailed genes. J. Neurosci. 21, 3126-3134. doi: 10.1523/jneurosci.21-09-031 26.2001

Son, J. H., Min, N., and Joh, T. H. (1996). Early ontogeny of catecholaminergic cell lineage in brain and peripheral neurons monitored by tyrosine hydroxylase-lacZ transgene. Mol. Brain Res. 36, 300-308. doi: 10.1016/0169$328 \mathrm{x}(95) 00255-\mathrm{q}$

Spassky, N., de Castro, F., Le Bras, B., Heydon, K., Quéraud-LeSaux, F., Bloch-Gallego, E., et al. (2002). Directional guidance of oligodendroglial migration by class 3 semaphorins and netrin-1. J. Neurosci. 22, 5992-6004. doi: 10.1523/jneurosci.22-14-05992.2002 
Stainier, D. Y., and Gilbert, W. (1989). The monoclonal antibody B30 recognizes a specific neuronal cell surface antigen in the developing mesencephalic trigeminal nucleus of the mouse. J. Neurosci. 9, 2468-2485. doi: 10.1523/jneurosci.09-07-02468.1989

Stainier, D. Y., and Gilbert, W. (1990). Pioneer neurons in the mouse trigeminal sensory system. Proc. Natl. Acad. Sci. U S A 87, 923-927. doi: 10.1073/pnas. 87.3.923

Tanaka, D. H., Maekawa, K., Yanagawa, Y., Obata, K., and Murakami, F. (2006). Multidirectional and multizonal tangential migration of GABAergic interneurons in the developing cerebral cortex. Development 133, 2167-2176. doi: 10.1242/dev.02382

Vasudevan, A., Won, C., Li, S., Erdelyi, F., Szabo, G., and Kim, K.S. (2012). Dopaminergic neurons modulate GABA neuron migration in the embryonic midbrain. Development 139, 3136-3141. doi: 10.1242/dev. 078394

Xu, B., Goldman, J. S., Rymar, V. V., Forget, C., Lo, P. S., Bull, S. J., et al. (2010). Critical roles for the netrin receptor deleted in colorectal cancer in dopaminergic neuronal precursor migration, axon guidance, and axon arborization. Neuroscience 169, 932-949. doi: 10.1016/j.neuroscience.2010. 05.025
Yang, S., Edman, L. C., Sanchez-Alcaniz, J. A., Fritz, N., Bonilla, S., Hecht, J., et al. (2013). Cxcl12/Cxcr4 signaling controls the migration and process orientation of A9-A10 dopaminergic neurons. Development 140, 4554-4564. doi: 10.1242/dev.098145

Zervas, M., Millet, S., Ahn, S., and Joyner, A. L. (2004). Cell behaviors and genetic lineages of the mesencephalon and rhombomere 1 . Neuron 43, 345-357. doi: 10.1016/j.neuron.2004.07.010

Conflict of Interest Statement: The authors declare that the research was conducted in the absence of any commercial or financial relationships that could be construed as a potential conflict of interest.

Copyright (C) 2018 García-Peña, Ávila-González, Miquelajáuregui, Lozano-Flores, Mastick, Tamariz and Varela-Echavarría. This is an open-access article distributed under the terms of the Creative Commons Attribution License (CC BY). The use, distribution or reproduction in other forums is permitted, provided the original author(s) and the copyright owner(s) are credited and that the original publication in this journal is cited, in accordance with accepted academic practice. No use, distribution or reproduction is permitted which does not comply with these terms. 